\title{
The kinase haspin is required for mitotic histone H3 Thr 3 phosphorylation and normal metaphase chromosome alignment
}

\author{
Jun Dai, ${ }^{1}$ Sammy Sultan, ${ }^{1}$ Stephen S. Taylor, ${ }^{2}$ and Jonathan M.G. Higgins ${ }^{1,3}$ \\ ${ }^{1}$ Division of Rheumatology, Immunology and Allergy, Department of Medicine, Brigham and Women's Hospital, \\ Harvard Medical School, Boston, Massachusetts 02115, USA; ${ }^{2}$ Faculty of Life Sciences, University of Manchester, \\ Manchester M13 9PT, United Kingdom
}

\begin{abstract}
Post-translational modifications of conserved $\mathrm{N}$-terminal tail residues in histones regulate many aspects of chromosome activity. Thr 3 of histone $\mathrm{H} 3$ is highly conserved, but the significance of its phosphorylation is unclear, and the identity of the corresponding kinase unknown. Immunostaining with phospho-specific antibodies in mammalian cells reveals mitotic phosphorylation of $\mathrm{H} 3 \mathrm{Thr} 3$ in prophase and its dephosphorylation during anaphase. Furthermore we find that haspin, a member of a distinctive group of protein kinases present in diverse eukaryotes, phosphorylates $\mathrm{H3}$ at Thr 3 in vitro. Importantly, depletion of haspin by RNA interference reveals that this kinase is required for $\mathrm{H} 3 \mathrm{Thr} 3$ phosphorylation in mitotic cells. In addition to its chromosomal association, haspin is found at the centrosomes and spindle during mitosis. Haspin RNA interference causes misalignment of metaphase chromosomes, and overexpression delays progression through early mitosis. This work reveals a new kinase involved in composing the histone code and adds haspin to the select group of kinases that integrate regulation of chromosome and spindle function during mitosis and meiosis.
\end{abstract}

[Keywords: Chromatin; centromere; mitosis; serine/threonine kinase; histone modification; chromosome congression]

Supplemental material is available at http://www.genesdev.org.

Received September 29, 2004; revised version accepted December 17, 2004.

To facilitate cell division, the processes of chromatin condensation, chromosome alignment on a bipolar spindle, chromosome separation, and cytokinesis must occur in a defined sequence. To ensure this orderly progression, the regulation of chromatin structure and spindle activity must be precisely integrated and checkpoints must be satisfied before subsequent steps are allowed. Errors in coordinating these events can lead to genomic instability and aneuploidy, contributing to the generation of cancer and birth defects. The elucidation of these regulatory mechanisms therefore is a major goal of current cell biology. To date, a select group of kinases has been found to orchestrate mitosis. In particular, members of the cyclin-dependent kinase, Aurora, Polo, and NIMA/Nek families phosphorylate substrates in chromatin and at the spindle apparatus to regulate events during cell division and to signal the outcome of the various checkpoints (Nigg 2001).

In chromatin, the core histones $\mathrm{H} 3, \mathrm{H} 2 \mathrm{~B}, \mathrm{H} 2 \mathrm{~A}$, and $\mathrm{H} 4$

${ }^{3}$ Corresponding author.

E-MAIL jhiggins@rics.bwh.harvard.edu; FAX (617) 525-1010.

Article published online ahead of print. Article and publication date are at http://www.genesdev.org/cgi/doi/10.1101/gad.1267105. form nucleosomal octamers around which DNA is wound to form the basic organizing structure of the chromosome. There has been great excitement recently as the importance of phosphorylation, acetylation, methylation, and ubiquitinylation of the core histones has been revealed. These modifications produce a high degree of combinatorial complexity, the so-called "histone code," that forms the basis of a critical regulatory system in the control of chromatin structure (Jenuwein and Allis 2001; Turner 2002). Modulation of chromatin structure is of particular significance for cell division, as the chromosomes undergo extensive compaction prior to segregation.

Not surprisingly, histones are major targets of mitotic kinases. For example, histone H3 is extensively phosphorylated at Ser 10 during mitosis and meiosis (Hendzel et al. 1997; Prigent and Dimitrov 2003). The function of this modification is debated, but it may facilitate chromatin condensation or the release of cohesin and ISWI chromatin-remodeling ATPases (Van Hooser et al. 1998; Andrews et al. 2003; Prigent and Dimitrov 2003; Swedlow and Hirano 2003). A Tetrahymena strain with histone H3 mutated at Ser 10 showed perturbed chromatin condensation and abnormal chromosome segregation 
during meiosis and mitosis (Wei et al. 1999), while a similar mutation in Saccharomyces cerevisiae had no such effect (Hsu et al. 2000). Therefore, histone phosphorylation at Ser 10 has an important role in mitosis, but the extent to which it is required appears to be species dependent, perhaps because of redundancy provided by other mitotic histone modifications (Hsu et al. 2000). In fact, a number of highly conserved serine and threonine residues that might be phosphorylated are found in the core histones of all eukaryotes. Mitotic phosphorylation of Thr 11 (Preuss et al. 2003) and Ser 28 (Goto et al. 1999) of H3 and Thr 119 of Drosophila H2A (Aihara et al. 2004) have been reported.

The identities of protein kinases that phosphorylate the histones during mitosis in vivo remain somewhat uncertain. The best studied is aurora $\mathrm{B}, \mathrm{a}$ "chromosome passenger protein" that is located on the chromosomes during prophase and becomes concentrated at inner centromeres by metaphase before relocalizing to the spindle midzone at anaphase (Carmena and Earnshaw 2003). Consistent with this, aurora B has both chromatin and spindle-associated substrates and influences mitosis at a number of steps. Aurora B homologs play an important role in ensuring chromosome bi-orientation at metaphase by correcting mono-orientated attachments to the spindle, and are involved in normal chromatid separation and cytokinesis (Shannon and Salmon 2002; Andrews et al. 2003). They are also required for phosphorylation of the centromeric histone variant CENP-A at Ser 7 and of histone $\mathrm{H} 3$ at Ser 10 in many organisms (Hsu et al. 2000; Adams et al. 2001; Giet and Glover 2001; Petersen et al. 2001; Zeitlin et al. 2001; Crosio et al. 2002; Ditchfield et al. 2003; Hauf et al. 2003). It has not been possible, however, to unambiguously assign the role of mitotic histone H3 Ser 10 phosphorylation solely to aurora B (Nigg 2001; Prigent and Dimitrov 2003). Indeed, in Aspergillus, mitotic histone H3 Ser 10 phosphorylation is dependent on the kinase NIMA (De Souza et al. 2000). In addition, kinases that bring about the phosphorylation of other histone residues during mitosis must exist. The nature of these key enzymes remains unclear, although there is some evidence that aurora B, Dlk/ZIP kinase, and NHK-1 are responsible for mitotic phosphorylation of H3 Ser 28, Thr 11, and H2A Thr 119, respectively (Goto et al. 2002; Preuss et al. 2003; Aihara et al. 2004).

Haspin/Gsg2 (haploid germ cell-specific nuclear protein kinase/germ cell-specific gene-2) was first identified as a testis-specific gene in mice (Tanaka et al. 1994, 1999). We identified the human haspin gene and confirmed that haspin mRNA levels are highest in testis. In addition, in both humans and mice we detected lower levels of haspin mRNA in other organs and in all proliferating cell lines tested, suggesting that expression of haspin is not truly haploid germ cell-specific (Higgins 2001a). Genes encoding haspin homologs are present in all major eukaryotic phyla, including yeasts, microsporidia, plants, nematodes, flies, fish, amphibians, and mammals (Higgins 2003). These haspin genes encode proteins that contain a distinctive C-terminal putative kinase domain and together constitute a novel eukary- otic protein kinase family (Higgins 2001b). The N-terminal portion of the haspin proteins is less conserved among species and has no clear homology with known domains (Tanaka et al. 1999; Yoshimura et al. 2001; Higgins 2003).

In this study we show that phosphorylation of Thr 3 of histone $\mathrm{H} 3$ occurs during mitosis and that the major kinase responsible for this modification in cultured cells is haspin. Overexpression and RNA interference experiments show that haspin is required for normal mitotic chromosome alignment. Consistent with this function, haspin associates with chromatin and spindle components and is phosphorylated during mitosis.

\section{Results}

Subcellular localization of haspin

To determine the subcellular localization of haspin, we transfected HeLa cells with myc-tagged human haspin and conducted anti-myc immunofluorescence staining. Myc-haspin was found exclusively in the nucleus during interphase. More intense staining was evident surrounding subnuclear structures (Fig. 1A). A similar haspin pattern was reported previously in transfected HEK293 and COS cells, although the identity of the compartment was not determined (Tanaka et al. 1999, 2001). Double staining with anti-myc and antibodies to B23/nucleophosmin (Fig. 1A) demonstrated that these structures are the nucleoli. Confocal fluorescence microscopy at $37^{\circ} \mathrm{C}$ of live HeLa cells transfected with EGFP-haspin confirmed that haspin localized to the nucleus in a pattern similar to that of DNA. The accumulation at perinucleolar regions was not as clear as that seen in fixed cells (Fig. 1B), suggesting that fixation preferentially stabilizes nucleolar haspin.

In fixed mitotic cells, myc-haspin (Supplementary Fig. 1A) and EGFP-haspin (data not shown) were found associated with the condensed chromosomes in prophase through anaphase. In metaphase spreads, myc-haspin was found on chromosome arms, but the most intense staining was in centromeric regions (Fig. 1C). When we visualized live HeLa cells at $37^{\circ} \mathrm{C}$ by video microscopy, EGFP-haspin was present on the condensing chromosomes in prophase, and remained associated with the condensed chromosomes throughout mitosis (Fig. 1D; Supplementary Movie). We then examined haspin localization in more detail by confocal microscopy of live mitotic cells (Fig. 1B). In addition to the localization of EGFP-haspin on chromosomes, it also appeared at centrosomes in prometaphase through telophase. Weaker localization of EGFP-haspin to spindle fibers emanating from the centrosome was apparent from metaphase on, as was localization of EGFP-haspin to the midbody of telophase cells. The localization of EGFP-haspin and $\alpha$-tubulin in fixed cells confirmed that haspin was associated with spindle poles (Fig. 1E). EGFP alone was found exclusively in the cytoplasm of mitotic cells (data not shown).

To assess the localization of untagged haspin, we pro- 
A

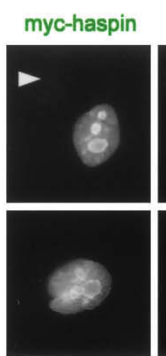

myc-haspin
DNA

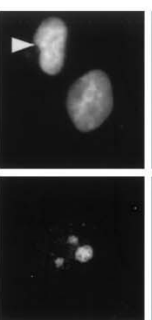

B23

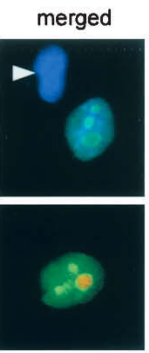

merged

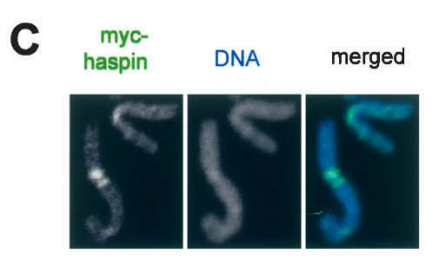

D

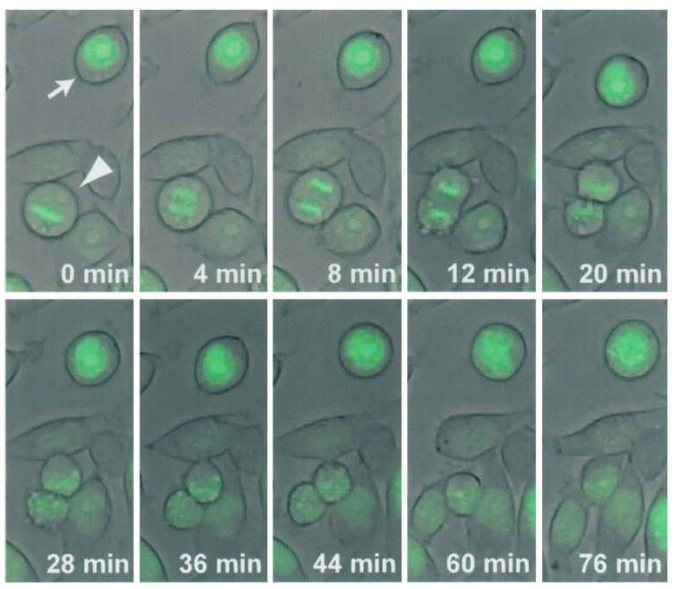

B

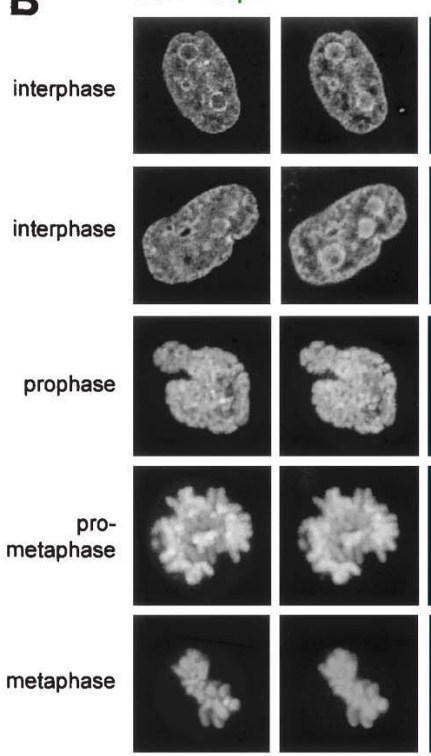

merged
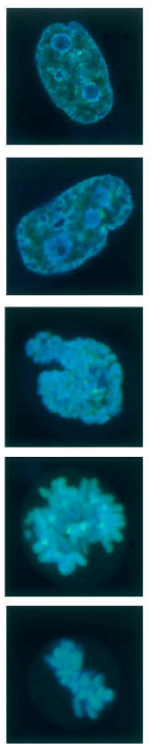

EGFP-haspin
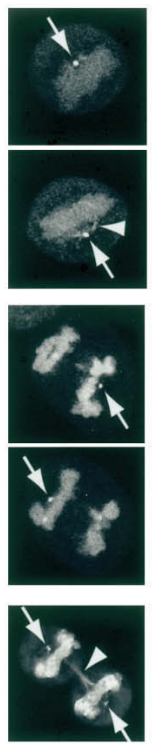

DNA
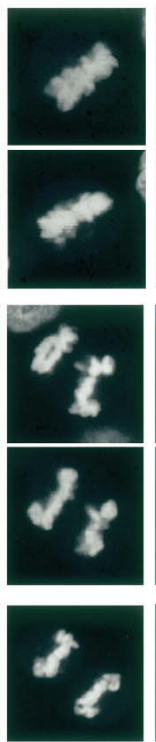

merged
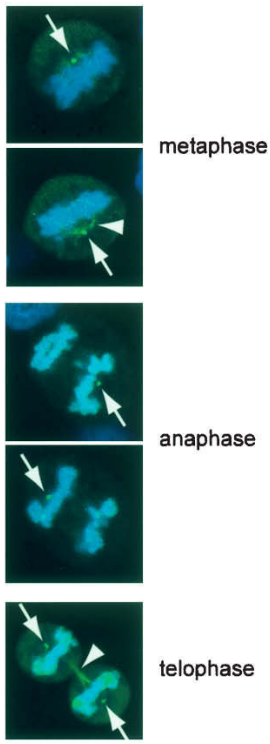

anaphase

\section{E}

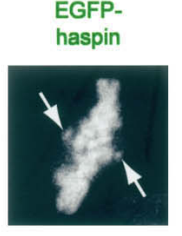

DNA

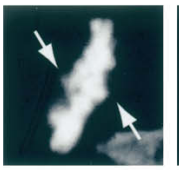

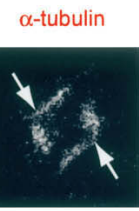

merged

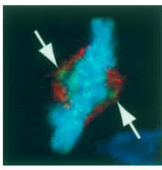

Figure 1. Haspin is a nuclear protein during interphase and associates with the chromosomes and spindle apparatus during mitosis. (A) Interphase HeLa cells transiently transfected with a vector encoding myc-haspin were analyzed by immunofluorescent staining with anti-myc-FITC (green) and anti-nucleophosmin/B23 followed by anti-goat IgG-Cy3 antibodies (red). DNA was visualized with Hoechst 33342. The arrowhead indicates a nontransfected cell. (B) Live cell confocal fluorescence microscopy of HeLa cells stably transfected with a vector encoding EGFP-haspin under a doxycycline-inducible promoter and treated with doxycycline for $1 \mathrm{~d}$. DNA was visualized with the cell-permeable dye DRAQ5 (blue). Images on the left are projections of confocal image stacks and those on the right show individual confocal sections from a single metaphase, anaphase, and telophase cell. Arrows indicate the presence of haspin at the centrosomes, and arrowheads indicate haspin associated with the spindle. $(C)$ Metaphase chromosome spreads from myc-haspin transfected HeLa cells were fixed and stained with anti-myc-FITC (green) and DNA was visualized with DRAQ5 (blue). (D) HeLa cells treated as in $B$ were analyzed by live cell epifluorescence video microscopy at $37^{\circ} \mathrm{C}$. Selected images of EGFP fluorescence (green) are shown superimposed on corresponding bright-field images. The entire series is available as a Supplementary Movie. (E) Confocal immunofluorescence microscopy of a metaphase HeLa cell expressing EGFP-haspin (green), treated with $0.2 \%$ Triton X-100 in PHEM buffer followed by $3 \%$ formaldehyde. DNA was visualized with DRAQ5 (blue) and mouse anti- $\alpha$-tubulin staining with anti-mouse IgG-Cy3 (red). Arrows indicate the presence of haspin but not DNA at the spindle poles.

duced an affinity-purified polyclonal antibody to a peptide representing human haspin amino acids 329-344. By immunoblotting, we found the antibody was specific for haspin in transfected HEK293 cells (Fig. 2A) and HeLa cells (see Fig. 5A, below), but was unable to detect endogenous haspin. Upon fractionation of transfected cells into nucleus and cytoplasm-enriched fractions by hypotonic lysis, haspin was found only in the nuclear fraction
(Fig. 2A). Immunofluorescence of transfected untagged haspin in HeLa cells with this antibody confirmed nuclear localization in interphase, as well as chromosomal association during mitosis (data not shown). Although EGFPhaspin can be detected at the centrosome in fixed cells (Fig. 1E), we have so far been unable to establish a fixation technique that allows immunostaining of haspin or myc-haspin at the spindle or centrosome. 
A

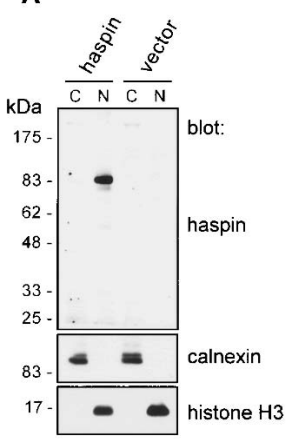

B

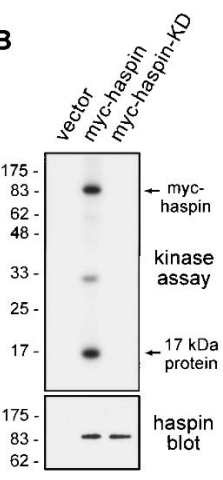

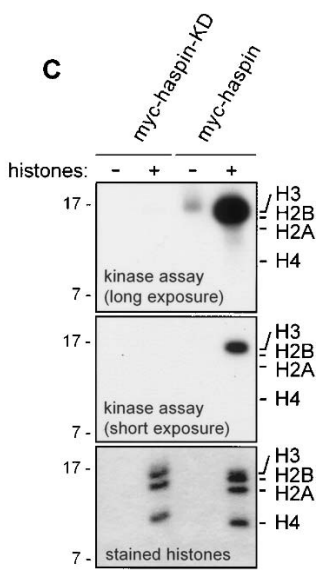

E

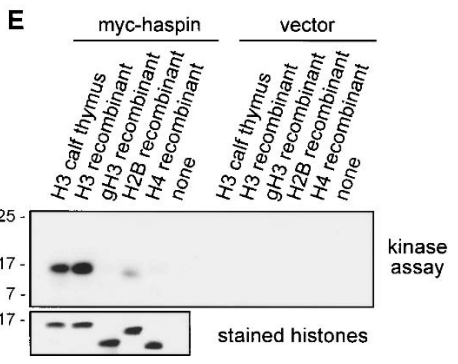

Figure 2. Haspin is a histone $\mathrm{H} 3$ kinase in vitro. $(A)$ HEK293 cells were transiently transfected with a vector encoding human haspin or vector alone. Fractions enriched for cytoplasmic (C) and nuclear (N) components were obtained by hypotonic lysis and analyzed by immunoblotting with affinity-purified rabbit antihaspin 32944 antibodies. Appropriate fractionation was verified by immunoblotting for the endoplasmic reticulum protein calnexin and the nuclear protein histone H3. (B) HEK293 cells were transiently transfected with vectors encoding myc-haspin or myc-haspin-KD or with vector alone. Rabbit antihaspin immunoprecipitates from lysed cells were subjected to in vitro kinase reactions with $\gamma^{32} \mathrm{P}$-ATP as described in Materials and Methods. That equivalent amounts of myc-haspin and myc-haspin-KD were present in the immunoprecipitates was verified by immunoblotting with rabbit antihaspin antibodies. $(C)$ In vitro kinase reactions of myc-haspin or myc-haspin-KD with or without the addition of purified calf thymus histones as an exogenous substrate were carried out as described in $B$. The positions of the histones in the gel were determined by Coomassie blue staining. $(D)$ In vitro kinase reactions of rabbit antihaspin immunoprecipitates from myc-haspin- or vector-alone-transfected HeLa cells using intact polynucleosomes (with or without the linker histone $\mathrm{H} 1$ ) as exogenous substrates were carried out as described in $B .(E)$ In vitro kinase reactions of rabbit antihaspin immunoprecipitates from myc-haspin- or vectoralone-transfected HEK293 cells with recombinant Xenopus histones purified from E. coli as exogenous substrates were carried out as described in $B$. (gH3) Tailless histone $\mathrm{H} 3$.

\section{Haspin is a histone H3 kinase}

We next examined the in vitro kinase activity of haspin. For these experiments we prepared a control haspin protein (myc-haspin-KD) containing a mutation of a single conserved lysine residue (K511A) that is critical for activity in essentially all protein kinases. Immunoprecipitates from vector-alone-, myc-haspin-, and myc-haspinKD-transfected HEK293 cell lysates were subjected to in vitro kinase assays in the presence of $\gamma^{32}$ P-ATP (Fig. 2B). While no phosphorylated proteins were generated in assays of vector-transfected cells, a radiolabeled band of $\sim 85 \mathrm{kDa}$ was visible in myc-haspin immunoprecipitates. This band coincided with the position of myc-haspin detected by immunoblotting, suggesting that myc-haspin had undergone autophosphorylation (Fig. 2B). No such phosphorylation was apparent when myc-haspin-KD immunoprecipitates were examined, providing evidence that the kinase activity observed is intrinsic to the haspin kinase domain.

Importantly, in the in vitro kinase assays with mychaspin immunoprecipitates from both HEK293 (Fig. 2B) and HeLa cells (data not shown), we observed an additional phosphorylated band of $\sim 17 \mathrm{kDa}$. One possibility was that this was a protein directly immunoprecipitated by the antihaspin antibody due to cross-reactivity. Similar results were obtained, however, when myc-haspin was immunoprecipitated with an anti-myc tag monoclonal antibody (data not shown), indicating that this was not the case. We reasoned that the $17-\mathrm{kDa}$ protein might be a phosphorylation substrate that coimmuno- precipitates with haspin. Recognizing the chromosomal location of haspin during mitosis, and that the core histones are major cellular components that have molecular masses in the range of $14-17 \mathrm{kDa}$, we sought to determine if histones could serve as exogenous substrates for haspin. Strikingly, when a purified mixture of histones $\mathrm{H} 1, \mathrm{H} 3, \mathrm{H} 2 \mathrm{~B}, \mathrm{H} 2 \mathrm{~A}$, and $\mathrm{H} 4$ was tested, haspin showed exquisite selectivity for a single band of $\sim 17 \mathrm{kDa}$, remarkably similar in size to the endogenous phosphorylated band (Fig. 2C). No such band was obtained from in vitro kinase assays of myc-haspin-KD or vector only transfected cells. Based on an overlay of the autoradiogram with the Coomassie blue-stained SDS-PAGE gel, the phosphorylated band appeared to coincide with histone $\mathrm{H} 3$. When purified histones were tested separately as targets for haspin kinase activity, we confirmed that histone $\mathrm{H} 3$ was the most efficiently phosphorylated, although in this situation weaker phosphorylation of other histones was also observed (Supplementary Fig. 1B). In intact nucleosomes, haspin phosphorylated only histone H3 (Fig. 2D). Recombinant histone H3 produced in Escherichia coli and lacking post-translational modifications (Luger et al. 1997) was also an efficient substrate for haspin activity (Fig. 2E), indicating that pre-existing histone modifications are not a requirement for haspin action in vitro. A recombinant form of histone $\mathrm{H} 3$ lacking the N-terminal 26 "tail" residues (gH3) was not phosphorylated by haspin (Fig. 2E), suggesting that the phosphorylation site resides within this region. Recombinant histones $\mathrm{H} 2 \mathrm{~B}$ and $\mathrm{H} 4$ were relatively poor substrates of haspin (Fig. 2E). We conclude that histone H3 can asso- 
Dai et al.

ciate with and serve as a substrate for the haspin kinase, at least in vitro.

\section{Haspin phosphorylates histone H3 at Thr 3}

The N-terminal tail regions of the histones are exposed in nucleosomal oligomers and are the major targets of the histone modifications so far analyzed (Jenuwein and Allis 2001; Turner 2002). To determine if haspin targets a residue in the $\mathrm{N}$-terminal tail of $\mathrm{H} 3$, we generated a protein (H3-GST) containing the first 45 residues of $\mathrm{H} 3$ fused to the $\mathrm{N}$ terminus of GST to preserve the normal orientation of the tail. Immunoprecipitates of mychaspin from transfected cells were able to phosphorylate
H3-GST but not GST alone or H2B-GST or H4-GST (Fig. 3A). To identify residues within the tail that are required for phosphorylation by haspin, we generated H3-GST proteins containing mutations to alanine of each of the seven serine and threonine residues present (T3A, T6A, S10A, T11A, T22A, S28A, T32A). The mutation T3A abolished phosphorylation by haspin, while the other mutant H3-GSTs behaved as wild type (Fig. 3A), suggesting that Thr 3 is the target of phosphorylation by haspin or that it is required for association of haspin with H3-GST.

To examine the interaction of haspin with $\mathrm{H} 3$, we utilized the H3-GST fusion proteins in "pulldown" assays from lysates of myc-haspin-transfected cells (Fig. 3B). In the conditions of the assay, myc-haspin bound to H3-
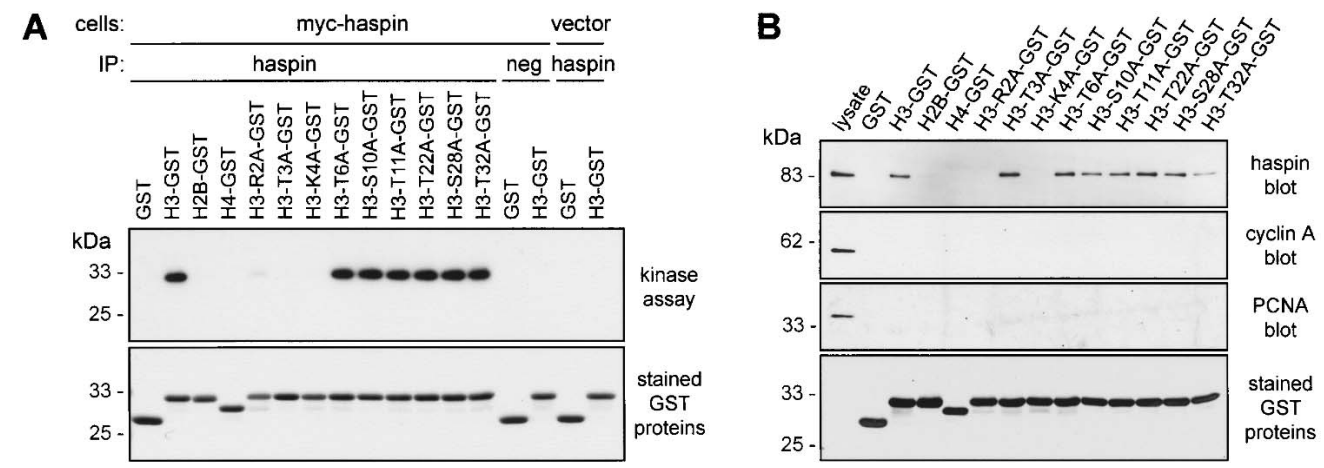

C
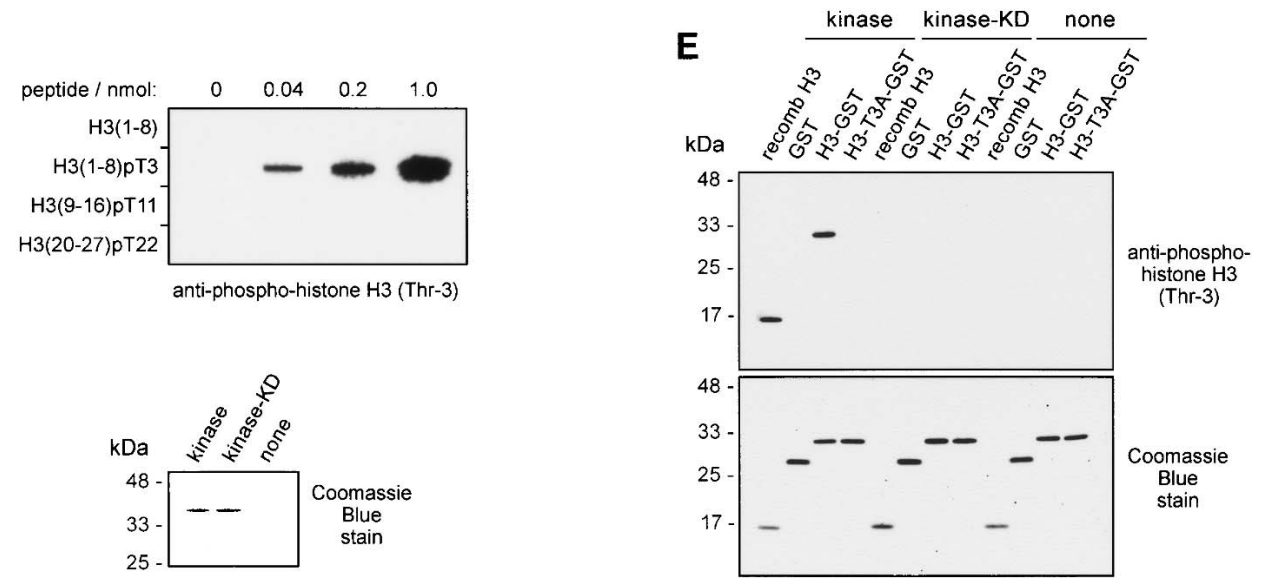

Figure 3. Haspin associates with histone $\mathrm{H} 3$ and phosphorylates it at Thr 3. (A) HeLa cells were transfected with vectors encoding myc-haspin or vector alone. Immunoprecipitates from cell lysates with rabbit antihaspin antibodies (haspin) or with nonimmune rabbit IgG (neg) were subjected to in vitro kinase assays with $\gamma^{32} \mathrm{P}$-ATP and histone tail-GST proteins as exogenous substrates. Equivalent loading of the GST proteins was verified by Coomassie blue staining. (B) Lysates of HEK293 cells transiently transfected with a vector encoding myc-haspin were incubated with glutathione-Sepharose beads coated with histone tail-GST proteins. After washing, the binding of myc-haspin, cyclin A, and PCNA to the beads was assessed by immunoblotting. The lane marked lysate was loaded with 1/20 volume of the input lysate, and equivalent loading of the GST proteins was verified by Coomassie blue staining of the blot. $(C)$ Peptides representing histone H3 amino acids 1-8 either without [H3(1-8)] or with phosphorylated Thr 3 [H3(1-8)pT3] or peptides containing phosphorylated Thr 11 [H3(9-16)pT11] or Thr 22 [H3(20-27)pT22] were immobilized by slot blotting and probed with rabbit anti-phospho-histone H3 (Thr-3) antibody B8634. Similar results were obtained with the commercial polyclonal antiphospho-histone $\mathrm{H} 3$ (Thr-3) antibody (Upstate), although some lower cross-reactivity with the phospho-Thr 22 peptide was observed in this case. $(D)$ Purified recombinant wild-type 6His-haspin kinase domain (kinase) or 6His-kinase containing the mutation K511A (kinase-KD) was examined by SDS-PAGE and Coomassie blue staining. (E) In vitro kinase reactions were carried out using 15 ng recombinant haspin 6His-kinase domain (kinase) or 6His-kinase-KD (kinase-KD) with $0.5 \mu \mathrm{g}$ purified recombinant H3, H3-GST, H3-T3A-GST, and GST alone as substrates. The products were analyzed by immunoblotting with rabbit anti-phospho-H3 (Thr-3), followed by staining with Coomassie blue to verify similar loading of substrate proteins. 
GST, whereas the binding of myc-haspin to GST alone, H2B-GST, and H4-GST was not detected. Importantly, the binding of H3-T3A-GST to myc-haspin was indistinguishable from wild type, indicating that the failure of haspin to phosphorylate this mutant is not due to a failure of the two proteins to associate. Mutation of residues adjacent to Thr 3 (R2A and K4A) abolished detectable association of haspin with H3-GST (Fig. 3B) and substantially reduced phosphorylation of H3-GST by haspin (Fig. 3A), indicating that these residues are involved in the interaction of haspin and histone $\mathrm{H} 3$.

To directly confirm that haspin phosphorylates Thr 3, we generated anti-phospho-histone $\mathrm{H} 3$ (Thr 3) antibodies (see Materials and Methods). First, to confirm the specificity of the antibodies, we demonstrated that they recognized a synthetic peptide representing residues 1-8 of the $\mathrm{H} 3$ tail when phosphorylated at Thr 3 but failed to bind to the equivalent nonphosphorylated peptide and to H3 peptides phosphorylated at Thr 11 or Thr 22 (Fig. 3C). Second, we produced a purified recombinant form of the kinase domain of human haspin as a 6 His-tagged fusion protein in $E$. coli and an equivalent protein containing the K511A mutation that is kinase deficient (Fig. 3D). We then carried out in vitro kinase reactions with a variety of purified substrates and used immunoblotting with anti-phospho-histone $\mathrm{H} 3$ (Thr 3) antibodies to detect phosphorylation of Thr 3 (Fig. 3E). The kinase domain of haspin, but not the kinase-KD form, was able to phosphorylate Thr 3 in recombinant histone $\mathrm{H} 3$ and in H3-GST. No such phosphorylation was detected on the H3-T3A-GST mutant or on GST alone. Together, these results reveal that both full-length haspin immunoprecipitated from transfected cells and the purified recombinant kinase domain of haspin specifically associate with and phosphorylate a novel residue within the tail of histone H3, Thr 3, at least in vitro.

\section{Histone H3 is phosphorylated on Thr 3 during mitosis}

We next wished to determine whether histone $\mathrm{H} 3$ is phosphorylated on Thr 3 in cultured cells and, if so, where and when. Prior to these studies, we further characterized recognition by the anti-phospho-histone $\mathrm{H} 3$ (Thr 3) antibodies of a variety of $\mathrm{H} 3$ peptides carrying other known modifications. This was important because the binding of other phospho-specific H3 antibodies is altered by the presence of flanking modifications (Turner 2002; Clayton and Mahadevan 2003). We tested biotinylated peptides representing residues $1-21$ of H3 carrying no modifications, asymmetric dimethylation on Arg 2, dimethylation on Lys 4 or Lys 9, acetylation on Lys 9 and Lys 14, or phosphorylation on Ser 10. All the peptides were similarly phosphorylated by the recombinant haspin kinase domain when the incorporation of radiolabeled phosphate from $\gamma^{32} \mathrm{P}$-ATP was assessed (Fig. 4A, right panel). In contrast, when the extent of peptide phosphorylation was determined by immunoblotting with the anti-phospho-histone $\mathrm{H} 3$ (Thr 3) antibody, it was clear that, alone among the tested modifications, methylation of Arg 2 substantially reduced, but did not eliminate, the recognition of phosphorylated Thr 3 (Fig. 4A, left panel). Similar results were obtained with two independent affinity-purified anti-phospho-histone H3 (Thr 3) antisera (see Materials and Methods).

To determine the timing of H3 Thr 3 phosphorylation, we synchronized HeLa cells at the G1/S boundary by double thymidine treatment and used the anti-phosphohistone H3 (Thr 3) antibody in immunoblot analysis of cell lysates at various times following release of the block. DNA content analysis was used to follow cell cycle progression, and the mitotic index was determined by staining with the antibody MPM- 2 as described (Taylor and McKeon 1997). MPM-2 recognizes a group of proteins that are phosphorylated in prophase, prometaphase, and metaphase and dephosphorylated during anaphase (Vandre and Borisy 1989). As expected, phosphorylation of $\mathrm{H} 3$ on Ser 10 and Ser 28 correlated well with the number of mitotic cells (Fig. 4B). Phosphorylation of $\mathrm{H} 3$ on Thr 3 showed a very similar pattern, suggesting that this modification, like that of Ser 10 and Ser 28, occurs primarily during mitosis.

We next examined the location and timing of $\mathrm{H} 3 \mathrm{Thr}$ 3 phosphorylation in HeLa cells by confocal immunofluorescence microscopy and compared it to that of Ser 10 phosphorylation (Fig. 4C). Little staining with antiphospho-histone H3 (Thr 3) antibodies was observed in the majority of interphase cells. Nevertheless, Thr 3 phosphorylation could be detected in a subset of cells without clear chromosome condensation. These cells were identical to those in which Ser 10 phosphorylation could first be detected (Fig. 4C), presumably late G2 cells as previously reported (Hendzel et al. 1997; Van Hooser et al. 1998). In prophase, phosphorylated Thr 3 was detected on condensing chromosomes, and prometaphase and metaphase chromosomes were strongly reactive with the antibody. The intensity of staining declined substantially during anaphase and was absent on decondensing chromosomes in telophase. Overall, the timing of Thr 3 phosphorylation and dephosphorylation was very similar to that of Ser 10. In contrast, there were differences in the location of the two modifications. In late G2 cells, Thr 3 phosphorylation appeared in a speckled pattern, whereas diffuse patches of Ser 10 phosphorylation frequently originating at the nuclear periphery were observed. The puncta of Thr 3 phosphorylation did not coincide with centromeres, suggesting that the modification originates at foci on chromosome arms. By late prophase the two modifications were partially overlapping and had spread over the majority of each chromosome, but the most intense staining for each modification was in distinct locations. Costaining with centromere antibodies in fixed cells and on spread metaphase chromosomes indicated that, from late prophase on, Thr 3 phosphorylation was strongest at inner centromeric regions, while that of Ser 10 was most intense at distinct bands on the chromosome arms (Fig. 4C,D; Supplementary Fig. 2A). Similar results were obtained in U2OS cells, although in this case phosphorylation of $\mathrm{H} 3$ at Ser 10 and Thr 3 was observed only after chromosome con- 
Dai et al.

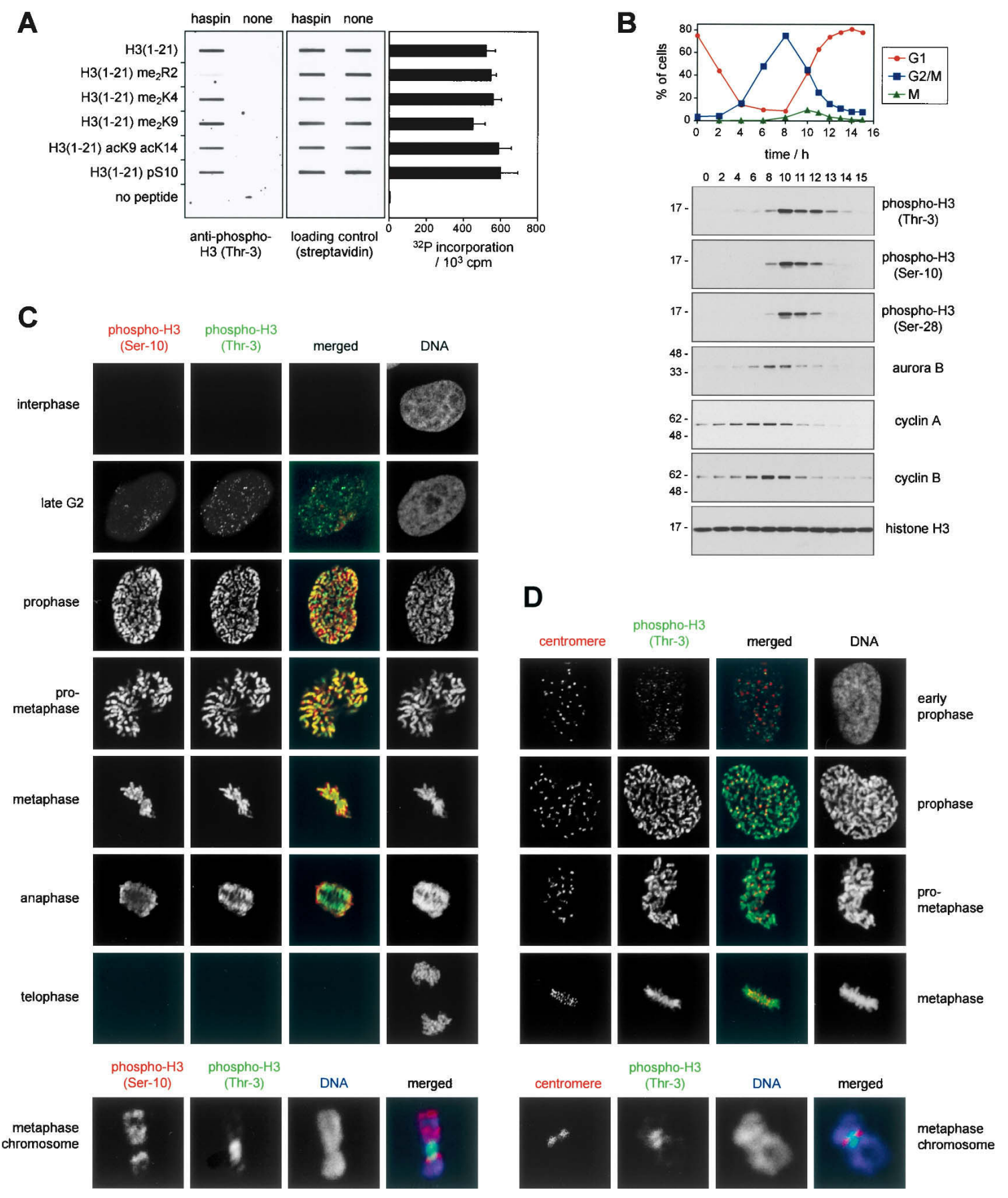

Figure 4. Histone $\mathrm{H} 3$ is phosphorylated at Thr 3 during mitosis. (A) Biotinylated peptides representing histone $\mathrm{H} 3$ residues 1-21 with various modifications were phosphorylated at Thr 3 in vitro using the haspin 6His-kinase domain (haspin) or were mock-treated in the absence of the kinase (none). (Right panel) The extent of phosphorylation was assessed by incorporation of radiolabeled phosphate from $\gamma^{32}$ P-ATP. Peptides immobilized by slot blotting were probed with rabbit anti-phospho-histone H3 (Thr-3) (left panel), and equivalent peptide loading was confirmed by streptavidin binding (center panel). Similar results were obtained with both anti-phospho-H3 (Thr-3) antibodies. (B) HeLa cells were synchronized at G1/S by double thymidine block. At various times following removal of thymidine, progression through the cell cycle was followed by propidium iodide staining for DNA content (G1 and G2/M) and MPM-2-FSE staining to enumerate mitotic cells $(\mathrm{M})$, and cell lysates were analyzed by immunoblotting as indicated. $(C)$ HeLa cells or metaphase spreads were fixed and stained with mouse anti-phospho-H3 (Ser-10) followed by anti-mouse IgG-Cy3 (red) and rabbit anti-phospho-H3 (Thr-3) followed by anti-rabbit IgG-Alexa488 (green). Cells were examined by confocal fluorescence microscopy, and the stages of mitosis were determined by the distinctive pattern of DNA visualized by DRAQ5 staining. (D) HeLa cells or metaphase spreads were stained as described in $C$ with human centromeric autoantibodies followed by antihuman IgG-Cy3 (red) and rabbit anti-phospho-H3 (Thr-3) followed by anti-rabbit IgG-Alexa488 (green). 
densation was apparent (Supplementary Fig. 2B,C). It is possible that changes in other histone modifications, particularly at Arg 2, influence the staining pattern observed with phospho-H3 (Thr 3) antibodies. Nevertheless, the most straightforward interpretation is that histone H3 is phosphorylated on Thr 3 during the initial stages of mitosis and dephosphorylated during anaphase.

\section{Haspin overexpression causes increased H3 Thr 3 phosphorylation and a delay during mitosis}

As a means to determine its function, we attempted to generate stable HeLa cell lines overexpressing haspin. Despite the ease with which we obtained stable transfectants with vector alone, stable clones from cells transfected with haspin all contained undetectable or aberrantly sized haspin proteins. This suggested that highlevel haspin expression is incompatible with cell growth. To circumvent this problem, we generated stable transfectants of HeLa Tet-On cells (BD Clontech) with mychaspin cDNA in the vector pTRE2pur and with vector alone as a control. In this system, the haspin gene is under an inducible promoter and is not expressed unless doxycycline is added. We obtained stable lines that express levels of myc-haspin undetectable by immunoblotting prior to induction, and maximal levels after 24-h treatment with $1 \mu \mathrm{g} / \mathrm{mL}$ doxycycline (Fig. 5A).
After induction, cells expressing myc-haspin showed a deficit in proliferation compared with uninduced cells (cell number reduced to $58 \%$ and $60 \%$ of uninduced control after $8 \mathrm{~d}$ in two separate experiments). Doxycycline had no such effect on the growth of cells transfected with vector alone (cell numbers were $104 \%$ and $115 \%$ of uninduced control after $8 \mathrm{~d}$ in two experiments). We then used DNA content analysis and MPM-2 staining to compare progression through the cell cycle of synchronized populations of myc-haspin and vector-transfected cells in inducing conditions. After release from a double thymidine block at G1/S, both myc-haspin and control cells progressed through $S$ phase and entered G2 with similar kinetics (Fig. 5B). Although entry into mitosis as defined by MPM-2 staining was similar in the two cell lines, the disappearance of the MPM-2 epitope was markedly delayed in myc-haspin-expressing cells (Fig. 5B), indicating a delay prior to anaphase. A similar effect was seen when induced and uninduced myc-haspin transfected cells were compared, while doxycycline treatment of vectortransfected cells had no effect on cell cycle progression (Supplementary Fig. 3A). It is unlikely that the kinase activity of haspin directly induces the MPM-2 phosphoepitope because no increase in the intensity of MPM-2 staining was observed in haspin-transfected cells /data not shown), and the extended period of mitosis was also reflected in a delay in exit from G2/M and entry into G1
A

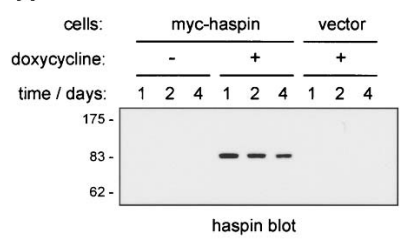

B
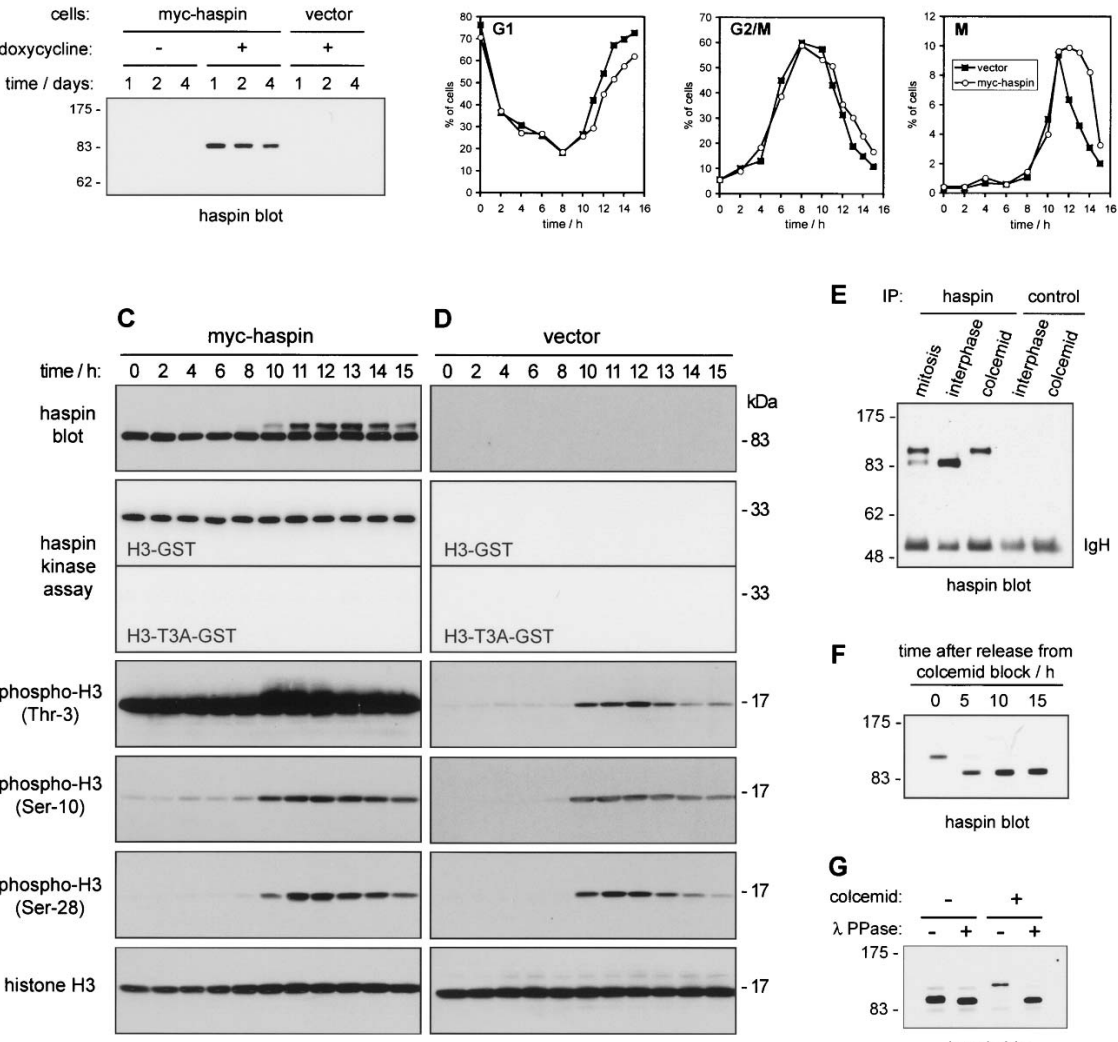

E

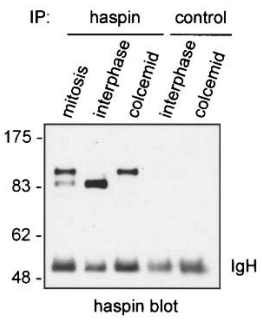

F time after release from

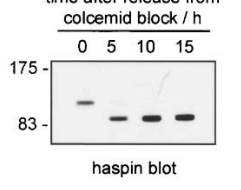

G

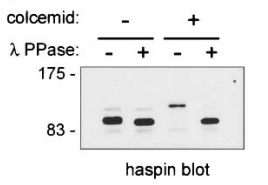

Figure 5. Haspin is phosphorylated during mitosis, and its overexpression delays mitotic progression. (A) HeLa Tet-On/mychaspin- or vector-alone-stably-transfected cells were induced with $1 \mu \mathrm{g} / \mathrm{mL}$ doxycycline for the times indicated, and mychaspin expression was assessed by rabbit antihaspin immunoblotting. (B) HeLa TetOn/myc-haspin- or vector-alone-stablytransfected cells were induced with $1 \mu \mathrm{g} /$ $\mathrm{mL}$ doxycycline for $24 \mathrm{~h}$ before synchronization at G1/S and analysis as described for Figure 4B. (C) Synchronized HeLa Tet-On/ myc-haspin cells as shown in $B$ were lysed and analyzed by immunoblotting and haspin in vitro kinase assay with $\gamma^{32}$ P-ATP using H3-GST or H3-T3A-GST as a control. (D) Synchronized HeLa Tet-On/vector cells as shown in $B$ were analyzed as described in C. $(E)$ Induced HeLa Tet-On/mychaspin cells were fractionated into looselyadherent mitotic (mitosis) and adherent interphase-enriched (interphase) populations or treated with colcemid prior to lysis. Rabbit antihaspin or rabbit IgG control immunoprecipitates were analyzed by rabbit antihaspin immunoblotting. (F) Induced HeLa Tet-On/myc-haspin cells were treated colcemid for $12 \mathrm{~h}$ prior to release. Whole-cell lysates made at the times indicated were analyzed by antihaspin immunoblotting. (G) Induced HeLa Tet-On/myc-haspin cells

were treated colcemid for $12 \mathrm{~h}$ or untreated prior to cell lysis. Antihaspin immunoprecipitates we
phosphatase as described in Materials and Methods and analyzed by antihaspin immunoblotting. 
as determined by DNA content (Fig. 5B; Supplementary Fig. 3A). Furthermore, in a separate experiment, enumeration of mitotic cells at $13 \mathrm{~h}$ following release revealed an accumulation in prophase/prometaphase and a corresponding decrease in the number of anaphase/telophase cells upon overexpression of myc-haspin (Supplementary Fig. 3B).

Immunoblotting of lysates from synchronized cells showed that myc-haspin protein was present at similar levels throughout the cell cycle (Fig. 5C). Interestingly however, the mobility of myc-haspin was significantly retarded at time points during which cells were undergoing mitosis, particularly at $11-14 \mathrm{~h}$ post-release (Fig. $5 \mathrm{C})$. In fact, myc-haspin in lysates of mitotic cells isolated by selective detachment, or after colcemid treatment, was almost entirely in this larger form (Fig. 5E). Myc-haspin returned to a size of $\sim 85 \mathrm{kDa}$ after release of cells from the mitotic block (Fig. 5F), and only this lower form was detected in interphase cells (Fig. 5C,E). Treatment of myc-haspin immunoprecipitated from colcemid-blocked cells with $\lambda$ phosphatase showed that the increase size during mitosis could be ascribed to phosphorylation (Fig. 5G). We conclude that haspin is strongly phosphorylated during mitosis.

To examine the kinase activity of overexpressed haspin through the cell cycle, we immunoprecipitated myc-haspin from the synchronized cell lysates and conducted in vitro kinase assays using H3-GST as a substrate or H3-T3A-GST as a negative control. Despite the clear phosphorylation of myc-haspin during mitosis, no change in its kinase activity was seen during the cell cycle. Consistent with this, we saw no difference in the activity of myc-haspin immunoprecipitated from mitotic cells obtained by selective detachment or colcemid block and interphase or asynchronous cells (data not shown).

To determine the effect of haspin overexpression on histone phosphorylation, we examined the synchronized cell lysates by immunoblotting with anti-phospho-histone $\mathrm{H} 3$ antibodies. In control cells, the phosphorylation of histone H3 on Thr 3, Ser 10, and Ser 28 correlated well with the number of mitotic cells, as expected (Fig. 5D). In myc-haspin-expressing cells, however, phosphorylation on Thr 3 was dramatically increased and was present throughout the cell cycle (Fig. 5C). In contrast, the intensity of Ser 10 and Ser 28 phosphorylation on H3 was not significantly altered by myc-haspin overexpression. These findings provide strong support for the hypothesis that haspin acts as a histone $\mathrm{H} 3 \mathrm{Thr} 3$ kinase in vivo.

\section{Endogenous haspin is responsible for histone H3 Thr 3 phosphorylation during mitosis}

We wished to determine the role of endogenous haspin during mitosis. Although the antihaspin antibody was unable to detect endogenous haspin in HeLa or HEK293 cells by immunoblotting, our previous Northern analyses suggested that all proliferating cell lines express haspin mRNA (Higgins 2001a). As a more sensitive approach to detect endogenous haspin activity, we ana- lyzed antihaspin immunoprecipitates from untransfected HeLa cells by in vitro kinase assay. This revealed a kinase activity that could phosphorylate H3-GST but not H3-T3A-GST (Fig. 6A), suggesting the presence of an H3 Thr 3 kinase, most likely endogenous haspin. No such activity was found in negative control immunoprecipitates (Fig. 6A). Note that longer autoradiographic exposures of gels were required to visualize endogenous kinase activity than those shown in Figures 2, 3, and 5 for overexpressed myc-haspin. The pattern of substrate specificity clearly differed from that of aurora B immunoprecipitated from mitotic HeLa cells, which efficiently phosphorylated H3-GST and H3-T3A-GST but not H3-S10A-GST, as expected (Fig. 6B).

When nocodazole-blocked cells or mitotic cells obtained by selective detachment were compared with an asynchronous or interphase population, no increase in the kinase activity of immunoprecipitated endogenous haspin was seen (Fig. 6B; data not shown). Indeed, when we examined endogenous haspin from cells synchronized at G1/S and then released, little change in kinase activity was seen during the cell cycle (Fig. 6C), confirming the results with overexpressed haspin (Fig. 5C). In contrast, the activity (Fig. 6B) and protein level (Fig. 4B) of aurora $B$ increase in $\mathrm{G} 2 / \mathrm{M}$ as previously reported (Bischoff et al. 1998). It should be noted, however, that we have been unable to directly determine the amount of endogenous haspin protein in cells and that our results do not rule out regulation of haspin activity during mitosis in vivo (see Discussion).

To determine whether endogenous haspin is required for phosphorylation of $\mathrm{H} 3$ on Thr 3, we conducted RNA interference. At $100 \mathrm{nM}$, transfection of small interfering RNA (siRNA) ID 1093-specific for human haspin reduces haspin mRNA levels in HeLa cells by $89 \% \pm 1 \%$ (Ambion). We confirmed that transfection of 20 or $100 \mathrm{nM}$ of this siRNA, but not of a negative control siRNA, reduced endogenous haspin kinase activity in both asynchronous and nocodazole-blocked mitotic HeLa cells (Fig. 6D). The treatment had little effect on the aurora B kinase activity detected in the same cell lysates. Strikingly, haspin siRNA dramatically reduced the phosphorylation of $\mathrm{H} 3$ on Thr 3 seen in mitotic cells (Fig. 6D). In contrast, no change was seen in the level of $\mathrm{H} 3$ phosphorylation on Ser 10. Haspin siRNA also caused a similar reduction in $\mathrm{H} 3 \mathrm{Thr} 3$ phosphorylation in U2OS cells (see Fig. 7A; data not shown) and, using a different murine haspin siRNA, in NIH3T3 cells (Fig. 6E). Inhibition of aurora B activity by ZM447439 treatment dramatically reduced histone H3 Ser 10 phosphorylation as reported previously (Ditchfield et al. 2003) but did not prevent Thr 3 phosphorylation (Supplementary Fig. 4). Therefore endogenous haspin, but not aurora B, activity is required for H3 phosphorylation on Thr 3 in mitotic cells.

\section{Depletion of haspin prevents normal metaphase chromosome alignment}

To examine the effect of haspin RNA interference on mitosis, we transfected U2OS and HeLa cells with 
A

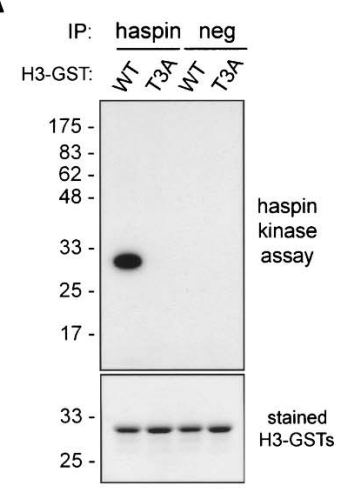

B

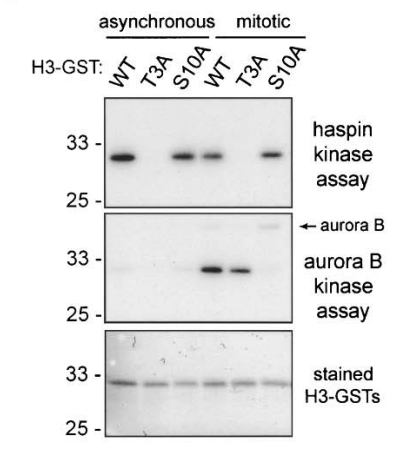

C

time /h: $0 \begin{array}{lllllllllll}2 & 4 & 6 & 8 & 10 & 11 & 12 & 13 & 14 & 15\end{array}$

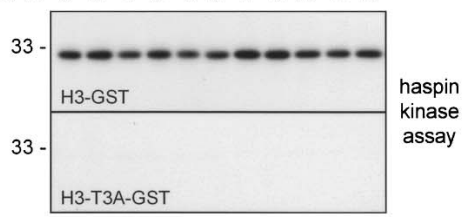

D

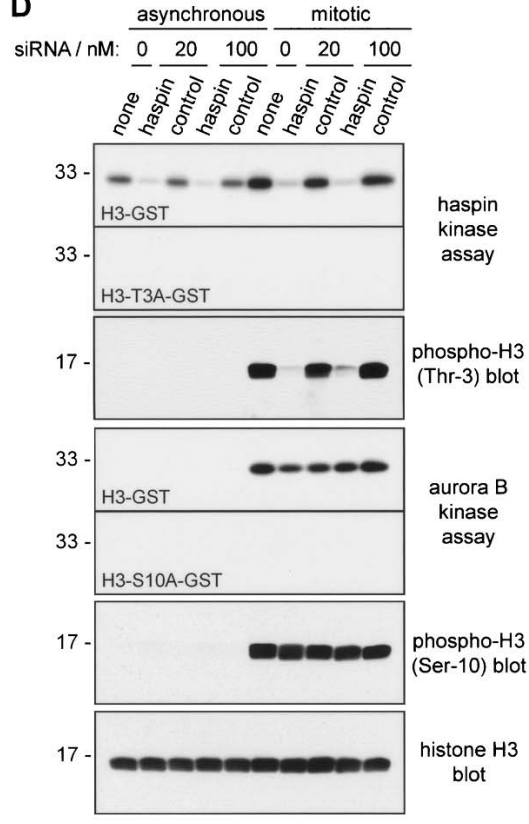

E

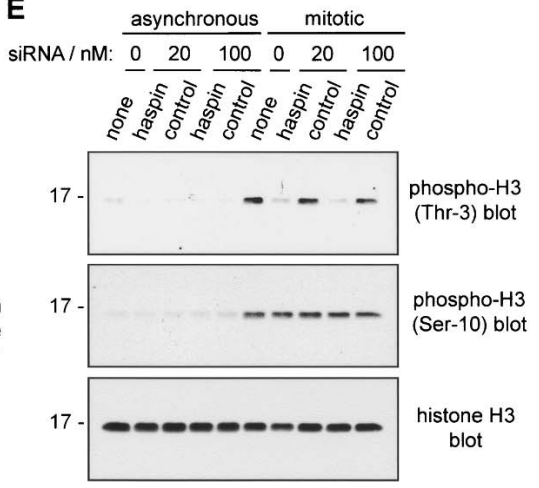

Figure 6. Endogenous haspin is required for phosphorylation of histone $\mathrm{H} 3$ on Thr 3. (A) Immunoprecipitates with rabbit antihaspin or rabbit IgG negative control (neg) antibodies from HeLa cell lysates were subjected to in vitro kinase assays with $\gamma^{32} \mathrm{P}$ ATP and H3-GST or H3-T3A-GST as substrates. Coomassie blue staining was used to confirm equivalent levels of GST proteins. (B) Antihaspin and anti-aurora B immunoprecipitates from HeLa cell lysates were subjected to in vitro kinase reactions with $\gamma^{32} \mathrm{P}-\mathrm{ATP}$ and H3-GST, H3-T3A-GST, or H3-S10A-GST proteins as substrates. Coomassie blue staining was used to confirm equivalent levels of GST proteins. (C) The synchronized HeLa TetOn/vector cells shown in Figure 5B were analyzed by haspin in vitro kinase assay described for Figure 5C. Note that this is a longer exposure of the autoradiogram shown in Figure 5D, carried out in order to visualize endogenous haspin activity. Similar results were obtained with HeLa cells (data not shown). (D) HeLa cells were transfected with haspin siRNA (Ambion ID \#1093), control siRNA (Ambion 4611), or no siRNA. Approximately $30 \mathrm{~h}$ after transfection, the cells were incubated with nocodazole for $16 \mathrm{~h}$ (mitotic) or left untreated (asynchronous) prior to lysis. Antihaspin and anti-aurora B immunoprecipitates were subjected to in vitro kinase reactions with $\gamma^{32}$ P-ATP and H3-GST, H3-T3A-GST, or H3-S10A-GST as substrates, and lysates were immunoblotted with anti-phospho-H3 (Thr-3) or antiphospho-H3 (Ser-10) antibodies. The anti-phosphoH3 (Thr-3) blot was stripped and reprobed with antihistone $\mathrm{H} 3$ antibodies. The increased haspin activity in nocodazole-treated cells was not a reproducible finding, as shown in $B$ and $C$. (E) NIH3T3 cells were transfected with mouse haspin (Ambion ID 67120) or negative control (Ambion 4611) siRNAs and analyzed as described for $D$. haspin or control siRNAs and assessed the distribution of chromosomes in mitotic cells by immunofluorescence. Among haspin siRNA-transfected U2OS cells, we noted an increased number with a late prometaphase configuration in which a partial metaphase plate was present, but many chromosomes were apparently "stranded" near the spindle poles (Fig. 7A). Staining with anticentromere antibodies revealed doublets on most of the unaligned chromosomes indicating that they were mono-orientated sister chromatid pairs. The centromeres of chromosomes that were present at the metaphase plate often appeared poorly aligned (Fig. 7A; data not shown). Enumeration of mitotic cells showed that haspin siRNA caused an accumulation of cells in prometaphase and a corresponding decrease in anaphase and telophase cells compared with controls (Fig. 7B; Supplementary Fig. 5A). We noted that within the haspin siRNA-treated population, H3 Thr 3 phosphorylation was reduced to varying extents in different cells. When we examined only those cells with low levels of Thr 3 phosphorylation ("low pT3"), the increased ratio of prometaphase over metaphase cells was particularly dra- matic (Fig. 7C). In cells with moderate to high levels of pT3, or in control transfectants, there was a 50\%:50\% split between cells classified as prometaphase and metaphase, and $<10 \%$ had a partial metaphase configuration. In contrast, among haspin siRNA transfected cells with low pT3 $>80 \%$ were in prometaphase and $<20 \%$ in metaphase. More than $40 \%$ had a partial metaphase arrangement similar to that shown in Figure 7A. Similar results were obtained with an independent haspin siRNA reagent (Fig. 7B,C) and in HeLa cells, although these cells apparently required more complete haspin depletion to disrupt mitosis (Supplementary Fig. 5B). We conclude that haspin is required for normal alignment of chromosomes at metaphase.

\section{Discussion}

\section{Haspin functions as a kinase during mitosis}

We show that, by a number of criteria, haspin is a kinase that functions in mitosis. First and most importantly, haspin overexpression or depletion results in defective 
Dai et al.

A
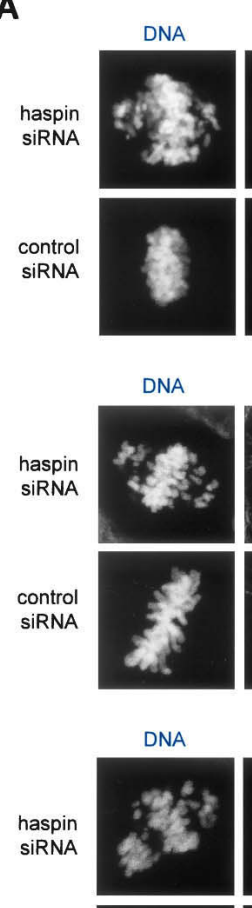

$\alpha-$ tubulin

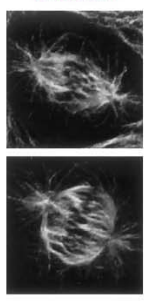

centromere
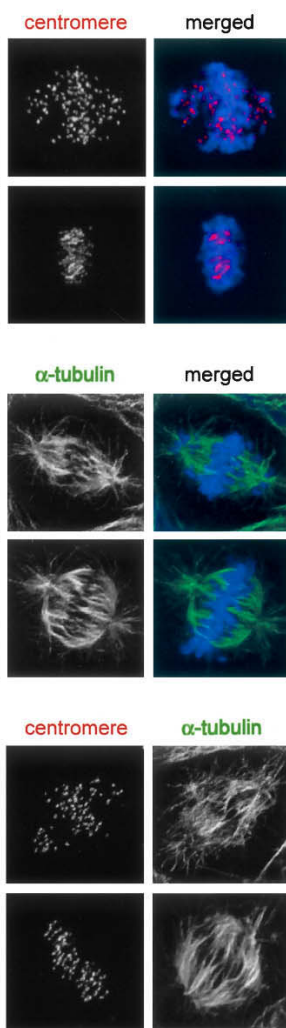

merged
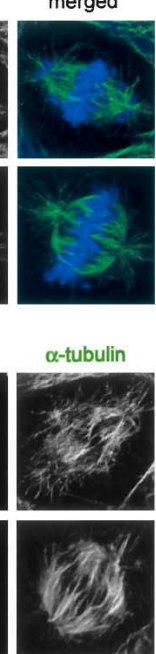
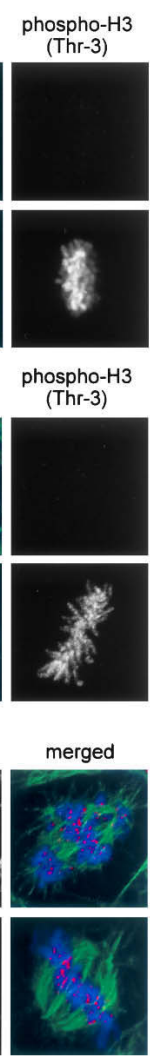

B
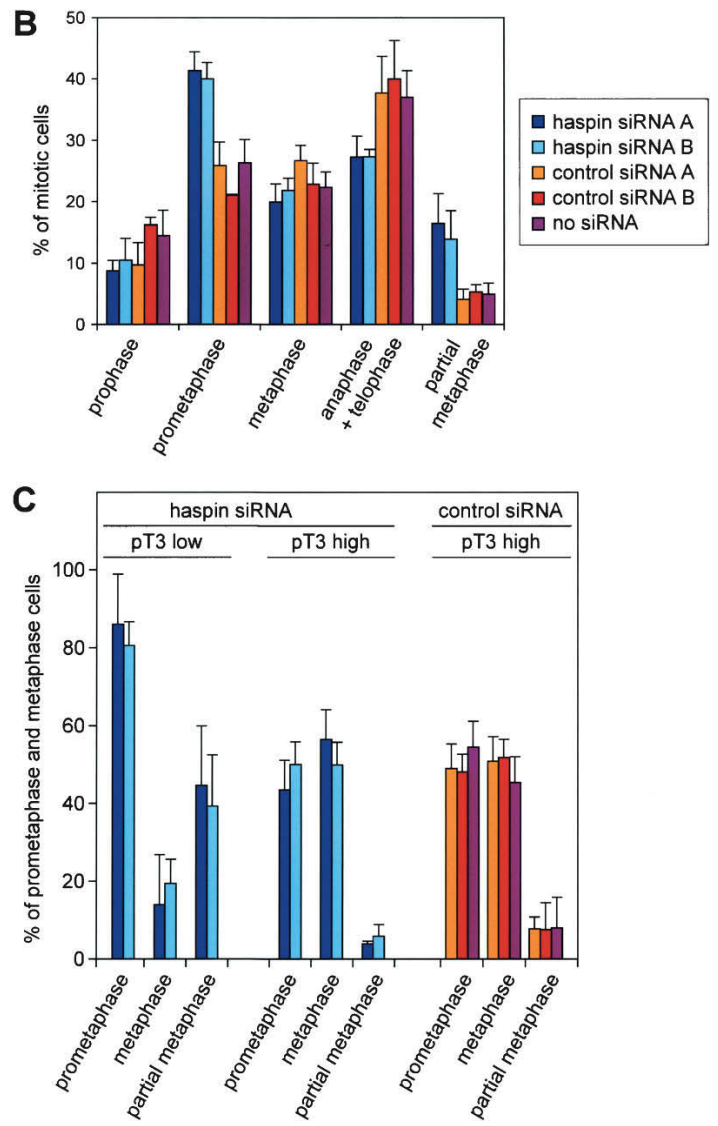

Figure 7. Depletion of haspin causes a failure of chromosome congression. (A) U2OS cells transfected with haspin siRNA (Ambion ID \#1093) or control siRNA (Ambion \#4613) were fixed and stained with DRAQ5 to visualize DNA and with human centromeric autoantibodies followed by antihuman IgG-Cy3 (red), mouse anti- $\alpha$-tubulin mAb followed by anti-mouse IgG-Alexa488 (green), and rabbit anti-phospho-H3 (Thr-3) followed by anti-rabbit IgG-Alexa488 (green) or anti-rabbit IgG-Cy3 (red) as indicated. (B) U2OS cells were transfected with haspin siRNA A (Ambion ID \#1093), haspin siRNA B (Dharmacon SMARTpool), control siRNA A (Ambion \#4613), or control siRNA B (Dharmacon SMARTpool), or without siRNA. After $48 \mathrm{~h}$, the cells were fixed and stained with propidium iodide, and $\sim 3000$ cells were counted on each of three coverslips for each condition and classified as interphase, prophase, prometaphase, metaphase, anaphase/telophase, or partial metaphase (a metaphase plate and three or more unaligned chromosomes; a subset of prometaphase) by the distinctive pattern of DNA staining. The percent of mitotic cells in each phase is shown. The increase in prometaphase and partial metaphase cells and the decrease in anaphase/telophase cells have $p<0.0001$ by two-tailed Student's $t$-test when comparing haspin siRNA A and B with control siRNA A, B, and no siRNA combined. (C) Haspin siRNA transfected U2OS cells in prometaphase and metaphase from $B$ stained with rabbit anti-phospho-H3 (Thr-3) followed by anti-rabbit IgG-Alexa488 were further classified as containing low or high levels of phosphorylated H3 Thr 3 (pT3). The percentage of these cells that were in prometaphase, metaphase, or partial metaphase is shown.

mitosis. Second, haspin has a unique pattern of association with critical components of the mitotic machinery. Third, phosphorylation of haspin and haspin-dependent phosphorylation of histone $\mathrm{H} 3$ occur specifically during mitosis.

Haspin localizes to condensed chromosomes throughout mitosis, to the centrosomes following nuclear envelope breakdown (NEBD), to spindle microtubules during metaphase and to the midbody in telophase. This localization is similar to that of aurora A and Polo-like kinase 1 (Plk1) except that these proteins are found at the centrosome prior to NEBD and, although Plk1 is found at centromeres, neither show prominent association with mitotic chromosome arms (Carmena and Earnshaw 2003; Barr et al. 2004). Like aurora B, haspin can associ- ate with condensing chromosomes, particularly at centromeric regions, and with spindle components. We found no evidence, however, that haspin undergoes the sudden transfer from chromosomes to the spindle typical of chromosome passenger proteins as anaphase begins (Carmena and Earnshaw 2003).

Interestingly, we could not detect a change in haspin kinase activity during the cell cycle, consistent with the lack of residues that can be phosphorylated in the potential activation loop of its kinase domain (Higgins 2001b). Despite this, we suspect that mitotic phosphorylation controls haspin function in vivo by modulating binding to protein(s) that regulate its activity or by regulating haspin association with proteins that target it to chromatin and the spindle. This type of targeting of aurora B 
by INCENP and survivin has been well described (Carmena and Earnshaw 2003). Such associations may be disrupted in the lysis conditions used in our experiments.

\section{Haspin is required for normal mitosis}

We find that haspin depletion by RNA interference prevents normal chromosome alignment at metaphase, while haspin overexpression results in a delay prior to metaphase. In common with mitotic kinases such as Plk1 and auroras A and B (Carmena and Earnshaw 2003; Barr et al. 2004), it appears that haspin activity must be maintained between certain limits and that either too much or too little prevents normal mitosis. The failure of chromosome congression upon reduction of haspin activity is reminiscent of the effect of aurora B depletion (Adams et al. 2001; Shannon and Salmon 2002; Andrews et al. 2003). It is possible that haspin plays a role in correcting syntelic chromosome attachments to the spindle, a normal process during formation of the metaphase plate that is dependent on aurora B (Andrews et al. 2003). We note also that the effect of haspin depletion is similar to that of disrupting the function of centromeric kinesin-related proteins, particularly CENP-E, or of depleting the kinetochore kinase Bub1 (Schaar et al. 1997; Johnson et al. 2004). Haspin may therefore play a role in regulating kinetochore assembly and spindle attachment or in modulating the activity of microtubule motors responsible for chromosome movement.

In the only other reported functional study of haspin, Tanaka et al. (1999) found that transient transfection of HEK293 cells with murine EGFP-haspin caused a profound decrease in the proportion of cells with G2/M DNA content and an accumulation in those with G1 DNA content after $4 \mathrm{~d}$. A mutated form of haspin that has 10 amino acids deleted from the kinase domain, and lacks kinase activity, caused the same effect after $2 \mathrm{~d}$ (Tanaka et al. 1999). The basis for the disparity with our results is not known. HEK293 cells are reported to have an ineffective spindle checkpoint (Kung et al. 1990), so it is possible that haspin-induced mitotic defects lead to subsequent activation of a G1 checkpoint in these cells. Alternatively, haspin might have another role in control of S-phase entry. To fully understand the function of haspin, it will be necessary to identify its substrates. We have identified one such substrate as Thr 3 of the core histone $\mathrm{H} 3$.

\section{Phosphorylation of histone H3 at Thr 3}

We show that during mitosis the core histone $\mathrm{H} 3$ is phosphorylated at Thr 3. Polioudaki et al. (2004) recently reported comparable results, although we extend these findings in two important ways. First, we find that the timing of onset of Ser 10 and Thr 3 phosphorylation is similar and can be detected prior to clear chromatin condensation in HeLa cells, likely late in G2 (Hendzel et al. 1997; Van Hooser et al. 1998). Second, we carried out coimmunostaining of phosphorylated Ser 10 and Thr 3, and show directly that they have distinct localizations during mitosis. Thr 3 phosphorylation appears to originate at foci on the chromosome arms. By metaphase, it is most intense at centromeric chromatin and is also present along the chromosome arms, reflecting the distribution of haspin. In contrast, Ser 10 phosphorylation was found primarily on chromosome arms in late prophase through metaphase. The two modifications are removed contemporaneously prior to chromosome decondensation in telophase.

The existence of a histone H3 Thr 3 kinase was first described 25 years ago. Shoemaker and Chalkley (1980) characterized a kinase activity associated with bovine thymus chromatin that displayed "extraordinary substrate specificity for histone H3" and phosphorylated Thr 3. More recently, an H3 Thr 3 kinase from avian nuclear envelope-associated peripheral heterochromatin that was able to form a complex with HP1 $\beta-G S T$ protein was described (Polioudaki et al. 2004). The identity of the kinase, however, was not determined in either study. Four lines of evidence lead us to conclude that haspin is the major kinase responsible for mitotic histone $\mathrm{H} 3 \mathrm{Thr}$ 3 phosphorylation, at least in HeLa, U2OS, and NIH3T3 cells. First, overexpression of myc-haspin leads to increased phosphorylation of $\mathrm{H} 3$ specifically at $\mathrm{Thr} 3$. Second, small inhibitory RNAs that deplete endogenous haspin activity dramatically reduce mitotic phosphorylation of $\mathrm{H} 3$ at Thr 3. Third, haspin associates with mitotic chromosomes at the time that $\mathrm{H} 3$ is phosphorylated on Thr 3. Fourth, haspin specifically associates with histone $\mathrm{H} 3$ and phosphorylates Thr 3 in vitro. The effects of overexpression and RNAi suggest that haspin is a component of the machinery required for $\mathrm{H} 3 \mathrm{Thr} 3$ phosphorylation during mitosis. When coupled with the finding that haspin associates with and phosphorylates H3 in vitro, these experiments provide persuasive evidence that haspin directly phosphorylates H3 in vivo.

\section{The function of mitotic histone H3 Thr 3 phosphorylation}

What might be the consequence of haspin-induced $\mathrm{H} 3$ Thr 3 phosphorylation? Although haspin siRNA did not prevent chromosome condensation (see Fig. 7A), our results do not rule out a more subtle effect on chromatin structure. The timing of Thr 3 phosphorylation suggests that it could play a role in facilitating condensation and/ or resolution of sister chromatids in late G2 and prophase. This might occur through alterations in the recruitment or function of condensins, cohesins, or topoisomerases (Swedlow and Hirano 2003). Defects in chromatin structure caused by inappropriate Thr 3 phosphorylation might hinder chromosome alignment later in mitosis, particularly given the importance of cohesion for bi-orientation (Tanaka 2002). Alternatively, its presence at inner centromere regions might reflect a more direct role for Thr 3 phosphorylation in regulating kinetochore assembly or function and the attachment or activity of spindle microtubules. Tension across paired kinetochores is critical to stabilize attachment of bi-ori- 
entated chromosomes to the spindle. It has been proposed that tension pulls kinetochores away from aurora $\mathrm{B}$ at the inner centromere, thereby regulating kinase access to its substrates and selectively stabilizing bi-orientated attachments (Tanaka 2002; Andrews et al. 2003). It is possible that phosphorylation of centromeric nucleosomes on Thr 3 of $\mathrm{H} 3$ influences transmission of tension between kinetochores and centromeric chromatin. This could affect separation of sister chromatids and impact chromosome bi-orientation, perhaps by altering aurora B activity.

At the molecular level, Thr 3 phosphorylation might directly influence internucleosomal contacts or could generate a binding site for regulatory proteins during mitosis, in much the same way that Lys 9 methylation facilitates HP1 binding (Lachner and Jenuwein 2002). Alternatively, it has been hypothesized that Thr 3 serves as a component of a "binary switch." Phosphorylation of Thr 3 could serve to eject as yet undefined proteins bound to the adjacent methylated Lys 4 residue (Fischle et al. 2003a). Dimethylation of Lys 4 in centromeric H3 has been reported (Sullivan and Karpen 2004). Lys 4 trior dimethylation is associated with an active or competent transcriptional state and a more "open" chromatin structure (Schneider et al. 2004), which might therefore be counteracted by Thr 3 phosphorylation during mitosis. Arg 2 in histone $\mathrm{H} 3$ can be methylated, too (Schurter et al. 2001), and similar interplay between Thr 3 and this residue could take place.

Cross-talk between nonadjacent histone modifications also occurs (Fischle et al. 2003b), and phosphorylation of Thr 3 might influence the binding or activity of other histone-modifying enzymes. Prior modifications might also impinge upon the ability of haspin to phosphorylate $\mathrm{H} 3$. We find that haspin phosphorylates recombinant $\mathrm{H} 3$ and chemically synthesized $\mathrm{H} 3$ peptides that lack amino acid modifications, and associates with and phosphorylates recombinant $\mathrm{H} 3-\mathrm{GST}$. In addition, H3 peptides containing a variety of modifications are equally good substrates for the haspin kinase domain (Fig. 4A). Together, these results suggest that haspin activity is not influenced by pre-existing $\mathrm{H} 3$ modifications in vitro. We cannot rule out, however, the possibility that haspin activity toward certain modified forms of $\mathrm{H} 3$ might be increased or decreased in vivo. This might occur because of the presence of combinations of histone modifications not tested in our in vitro study, the existence of other proteins in vivo that might compete for binding to modified $\mathrm{H} 3$, and the influence of the $\mathrm{N}$-domain of haspin that was not present in the recombinant haspin protein we used. Indeed, the association of full-length haspin with H3-GST is reduced by mutations at Arg 2 and Lys 4 (Fig. 3).

\section{Nonhistone targets of haspin activity}

It should be noted that it is unlikely that the sole target of haspin activity is histone $\mathrm{H} 3$, and therefore we cannot ascribe the effects of manipulating haspin activity only to its influence on H3 Thr 3 phosphorylation. The pres- ence of haspin at centrosomes and the spindle during mitosis strongly indicates that substrates will be found at these locations too. In fact, we have identified mitotic spindle and centrosomal proteins as potential haspinbinding proteins in a yeast two-hybrid screen, and we have noted spindle disruptions in mitosis following haspin siRNA treatment (J. Dai and J.M.G. Higgins, unpubl.). Haspin therefore has features in common with members of the Aurora, Nek, and Polo families that regulate the activity of both chromatin and spindle proteins at multiple stages of mitosis (Nigg 2001). Indeed, the overlap in haspin, Aurora, and Polo functions and localization suggest that it will be productive to investigate interactions between haspin and these other kinases.

\section{Conclusion}

To the best of our knowledge, an equivalent of Thr 3 is found in histone $\mathrm{H} 3$ of all eukaryotes, suggesting a highly conserved and critical function for this residue. Furthermore, the presence of haspin genes in diverse eukaryotes is suggestive of a crucial function in eukaryotic life (Higgins 2003). The limited information available regarding the two haspin homologs in budding yeast is consistent with the function of haspin that we describe. The mRNA levels of haspin homolog ALK1 are strikingly periodic during the mitotic cell cycle, with a peak in expression early in mitosis (Cho et al. 1998; Spellman et al. 1998). The second homolog, YBLO09W, is significantly induced during sporulation (Chu et al. 1998). The data suggest that Alk1p and Ybl009wp function during mitosis and meiosis, respectively (Higgins 2003). We propose that haspin is a member of the select group of kinases with a critical role in integrating the regulation of chromosome and spindle function during mitosis and probably meiosis. The high level of haspin in post-meiotic spermatids (Tanaka et al. 1999) also might suggest a role in the dramatic reorganization and compaction of chromatin that occurs during spermiogenesis. Further study of haspin function will help decipher the histone code and is likely to provide crucial insight into the mechanisms that maintain genomic stability during mitotic and meiotic cell division.

\section{Materials and methods}

\section{Antibodies, proteins, peptides, and cells}

A rabbit anti-serum to a KLH-conjugated peptide corresponding to residues 329-44 of human haspin ([C]DRLERTRSSRKSKHQE) was generated and affinity purified on the immunizing peptide by Zymed Laboratories Inc. The rabbit polyclonal antiserum B8634 to phospho-histone $\mathrm{H} 3$ (Thr 3) was produced by immunization with the peptide AR[pT]KQTAR(Ahx)C conjugated to BSA (Ahx indicates aminohexanoic acid), depleted using the equivalent non-phosphorylated peptide, and affinity purified on the phosphorylated peptide (Biosource). Alternatively, rabbit polyclonal antibody to phospho-histone $\mathrm{H} 3$ (Thr 3) from Upstate was used with similar results. Rabbit anti-phospho- 
histone $\mathrm{H} 3$ (Ser 28) was from Upstate, rabbit polyclonal and mouse monoclonal anti-phospho-histone H3 (Ser 10) from Cell Signaling Technology, and rabbit antihistone H3 from Abcam. Sheep antihuman aurora B was as described (Ditchfield et al. 2003). Goat anti-B23/nucleophosmin and mouse 9E10 antimyc-FITC were from Santa Cruz Biotechnology, and human autoantibody to centromeres was from Immunovision. Mouse AF8 monoclonal antihuman calnexin (Hochstenbach et al. 1992) was a gift from Dr Michael Brenner (Brigham and Women's Hospital, Boston, MA). Mouse monoclonal antibodies to human cyclin A, cyclin B, and PCNA were from BD Transduction Laboratories, and to $\alpha$-tubulin were from Sigma. Purified calf thymus histones were from Roche. Human polynucleosomes isolated from sonicated MCF-7 cell nuclei were provided by Dr Gavin Schnitzler (Tufts University, Boston, MA). Human histone H3 peptides H3(1-8), H3(1-8)pT3, H3(9-16)pT11, and $\mathrm{H} 3(20-27) \mathrm{pT} 22$, each with an additional Ahx and cysteine residue $(\approx 95 \%$ pure), were synthesized by Biosource. Other peptides were human $\mathrm{H} 3$ residues 1-21 followed by GGK-biotin and asymmetrically dimethylated at Arg 2 (>95\% pure, synthesized by Abgent), dimethylated at Lys 4 or Lys 9, acetylated at Lys 9 and Lys 14, or phosphorylated at Ser 10 (>90\% pure, Upstate). Human HEK293, HeLa, U2OS, and DLD-1 cells were maintained in $10 \%$ FBS/DMEM.

\section{Recombinant protein production}

Recombinant Xenopus H3, tailless H3 (gH3), H2B, and H4 histones, prepared according to Luger et al. (1997), were a gift from Dr Robert Kingston (Massachusetts General Hospital, Boston, MA). To generate plasmids encoding histone tail-GST proteins, PCR products encoding residues $1-45$ of human $\mathrm{H} 3$ (NM_003537) or 1-26 of human H4 (NM_003541) amplified from the plasmids pBOS-H3-N-GFP and pBOS-H4-N-GFP (kindly provided by Dr Hiroshi Kimura, Tokyo Medical and Dental University, Tokyo, Japan) (Kimura and Cook 2001) and a PCR product encoding residues 1-35 of H2B (NM_003526) amplified from human HeLa cell genomic DNA were inserted into the NcoI site of pETGEX-CT (a gift from Dr A.D. Sharrocks, University of Manchester, UK) (Sharrocks 1994). Site-directed mutants of H3-GST were generated by PCR mutagenesis. A construct encoding the 6His-tagged kinase domain was generated by insertion of a PCR product encoding residues 471-798 of human haspin into the PshAI site of the vector pET45b(+) (Novagen). An equivalent construct containing the mutation K511A was produced by PCR-based mutagenesis. All constructs were confirmed by DNA sequencing and introduced into $E$. coli strain BL21 (Novagen). GST and 6His fusion proteins were purified from IPTG-induced E. coli by standard procedures.

\section{Haspin expression in mammalian cells}

Using customized double stranded adapters, full-length human haspin cDNA (amino acids 1-798) (Higgins 2001a) was ligated into the HindIII-XbaI sites of the expression vector pcDNA3 (Invitrogen), and to generate myc-tagged haspin, cDNA encoding residues 2-798 was inserted into the pcDNA3-derived plasmid pCANmyc1. To generate a plasmid encoding EGFP-haspin, haspin cDNA encoding amino acids 2-798 was inserted into the SacII-BamHI sites of pEGFP-C1 (Clontech). To generate inducible vectors, cDNA encoding myc-haspin from pCANmychaspin (HindIII-EcoRV) was blunt-ended and inserted into the PvuII site of pTRE2/pur (BD Clontech), and NheI-XbaI fragments encoding EGFP-haspin or EGFP alone from pEGFPhaspin or pEGFP-C1, respectively, were ligated into the NheI site of pTRE2pur. All constructs were verified by DNA sequenc- ing. Transient transfection was carried out using Lipofectamine 2000 (Invitrogen). Stable transfection of HeLa Tet-On (BD Clontech) cells was carried out using Lipofectin with Plus Reagent (Invitrogen). After $24 \mathrm{~h}$, cells were transferred to 96-well plates and incubated in medium containing $1 \mu \mathrm{g} / \mathrm{mL}$ puromycin and $100 \mu \mathrm{g} / \mathrm{mL}$ G418. Clones expressing myc-haspin or EGFPhaspin in the presence, but not absence, of $1 \mu \mathrm{g} / \mathrm{mL}$ doxycycline were selected by anti-myc immunoblotting or flow cytometric analysis of EGFP fluorescence, respectively.

\section{Fluorescence microscopy}

Unless otherwise stated, cells or metaphase spreads were fixed with $4 \%$ paraformaldehyde/PBS for $10 \mathrm{~min}$, incubated in methanol for 5 min at $-20^{\circ} \mathrm{C}$; washed three times with $5 \%$ FBS/PBS over $30 \mathrm{~min}$; then incubated with $2 \mu \mathrm{g} / \mathrm{mL}$ anti-myc 9E10-FITC, $1 \mu \mathrm{g} / \mathrm{mL}$ goat anti-B23/nucleophosmin, $0.1 \mu \mathrm{g} / \mathrm{mL}$ mouse anti$\alpha$-tubulin, $1 / 4000$ human anti-centromere, $1 / 1000$ mouse antiphospho-histone $\mathrm{H} 3$ (Ser 10), or $0.2 \mu \mathrm{g} / \mathrm{mL}$ rabbit anti-phosphohistone $\mathrm{H} 3$ (Thr 3 ) in $5 \% \mathrm{FBS} / \mathrm{PBS}$ for $2 \mathrm{~h}$ at $25^{\circ} \mathrm{C}$ followed by $\sim 1$ $\mathrm{\mu g} / \mathrm{mL}$ donkey anti-goat, mouse, rabbit, or human IgG-Cy3 (Jackson ImmunoResearch) or goat anti-rabbit or mouse IgGAlexa488 (Invitrogen). To detect DNA, $0.5 \mu \mathrm{g} / \mathrm{mL}$ Hoechst 33342 (Sigma) or $2.5 \mu$ M DRAQ5 (Alexis) was used. Fluorescence microscopy was carried out by using a Nikon TE2000 inverted confocal microscope and video microscopy using a Nikon ECLIPSE E600 inverted fluorescence microscope, with heated stages at $37^{\circ} \mathrm{C}$ for live cell imaging.

\section{Cell synchronization}

Where necessary, HeLa Tet-On stable transfectants were incubated with $1 \mu \mathrm{g} / \mathrm{mL}$ doxycycline for $24-48 \mathrm{~h}$ prior to synchronization. Cells were synchronized at the G1/S boundary by double thymidine block (Spector et al. 1997) or in prometaphase by treatment with $50 \mathrm{ng} / \mathrm{mL}$ (HeLa) or $150 \mathrm{ng} / \mathrm{mL}$ (NIH3T3) nocodazole or $100 \mathrm{ng} / \mathrm{mL}$ colcemid for $12-16 \mathrm{~h}$. For cell cycle analysis, cells were permeabilized in $70 \%$ ice-cold ethanol, blocked with $1 \%$ BSA $/ 5 \%$ FBS, and stained with $10 \mu \mathrm{g} / \mathrm{mL}$ mouse monoclonal MPM-2-FSE (Upstate) (Taylor and McKeon 1997) followed by incubation in $50 \mu \mathrm{g} / \mathrm{mL}$ propidium iodide, $100 \mathrm{U} / \mathrm{mL}$ RNAse $\mathrm{A}$, and PBS for $1 \mathrm{~h}$ at $25^{\circ} \mathrm{C}$ to stain DNA. Analysis was conducted on a FACSort flow cytometer (BD Biosciences).

\section{Immunoprecipitation, GST pulldown, and immunoblotting}

For immunoprecipitation, cells were suspended in $50 \mathrm{mM}$ Tris/ $0.5 \mathrm{M} \mathrm{NaCl} / 1 \%$ Triton $\mathrm{X}-100 / 1 \%$ DOC/0.1\% SDS $/ 2 \mathrm{mM}$ EDTA at $\mathrm{pH} 7.4$ (buffer L) with $1 \mu \mathrm{g} / \mathrm{mL}$ pepstatin $/ 1 \mu \mathrm{g} / \mathrm{mL}$ leupeptin/1 $\mu \mathrm{g} / \mathrm{mL}$ antipain/1 $\mu \mathrm{g} / \mathrm{mL}$ chymostatin/1 $\mathrm{mM}$ phenylmethylsulphyl fluoride/ $1 \mathrm{mM} \mathrm{NaF} / 0.1 \mu \mathrm{M}$ okadaic acid and lysed by shearing 15 times through a 21 -gauge needle. Insoluble material was removed by centrifugation for $15 \mathrm{~min}$ at $13,000 \mathrm{rpm}$, the lysates precleared with protein G-Sepharose, and concentrations equalized based on Bradford assay (Bio-Rad Laboratories). Lysates were incubated with antibodies for $1.5 \mathrm{~h}$ at $4^{\circ} \mathrm{C}$ before addition of protein G-Sepharose for a further $1.5 \mathrm{~h}$. Beads were washed four times with buffer $\mathrm{L}$ and thrice with Hepes-buffered saline (HBS) at $\mathrm{pH}$ 7.4. For GST pulldown assays, cells were lysed in $20 \mathrm{mM}$ Tris/1\% Triton X-100/1 mM EDTA/1 mM DTT at pH 7.4 (buffer T) containing $0.3 \mathrm{M} \mathrm{NaCl}$ and protease and phosphatase inhibitors as above, clarified, and precleared with glutathione-Sepharose. Cell lysates (200 $\mu \mathrm{g}$ ) were incubated in $200 \mu \mathrm{L}$ buffer T containing $0.4 \mathrm{M} \mathrm{NaCl}$ for 1 $\mathrm{h}$ at $4^{\circ} \mathrm{C}$ with $2.5 \mu \mathrm{g}$ GST fusion protein preabsorbed to $5 \mu \mathrm{L}$ 
glutathione-Sepharose, followed by three washes in the same buffer. Whole-cell lysates for immunoblotting were prepared in $30 \mathrm{mM}$ Tris/1.5\% SDS/5\% glycerol/0.1\% bromophenol blue (pH 6.8). Hypotonic lysis in $10 \mathrm{mM}$ Hepes/0.5\% Triton X-100/ $1.5 \mathrm{mM} \mathrm{MgCl} 2 / 10 \mathrm{mM} \mathrm{KCl} \mathrm{(pH} \mathrm{7.4)} \mathrm{with} \mathrm{protease} \mathrm{inhibitors}$ was used to produce nuclear (pellet) and cytoplasm-enriched (supernatant) cell fractions. SDS-PAGE and immunoblotting were carried out using standard procedures (Coligan et al. 1994). Peptide slot blots to $0.2 \mu \mathrm{m}$ PVDF Immunblot membrane were carried out with the Bio-Dot SF apparatus (Bio-Rad Laboratories).

\section{In vitro kinase assays}

Haspin and aurora B kinase assays were conducted in $30 \mu \mathrm{L}$ $\mathrm{HBS} / 10 \mathrm{mM} \mathrm{MnCl} \mathrm{m}_{2}$ with $2.5 \mu \mathrm{M}$ ATP and $2.5 \mu \mathrm{Ci}\left[\gamma^{32} \mathrm{P}\right]$-ATP (3000 Ci $/ \mathrm{mmol}$ ) or with $100 \mu \mathrm{M}$ ATP for $15 \mathrm{~min}$ at $37^{\circ} \mathrm{C}$. Exogenous substrates were added at $0.5-1 \mu \mathrm{g}$ per reaction for histone and GST proteins and at $0.02-1 \mathrm{nmol}$ for peptides. Biotinylated peptides were quantified by HABA/avidin assay (Sigma). Incorporation of ${ }^{32} \mathrm{P}$ into histone and GST proteins was visualized by SDS-PAGE and autoradiography and into biotinylated peptides by immobilization on SAM ${ }^{2}$ Biotin Capture Membrane according the manufacturer's recommendations (Promega Corporation) and Cherenkov counting.

\section{Phosphatase treatment}

Myc-haspin immunoprecipitates from colcemid-treated or untreated induced HeLa Tet-On/myc-haspin cells were incubated with $200 \mathrm{U} \lambda$ phosphatase in $\lambda$ phosphatase buffer (New England Biolabs) or in buffer alone for $30 \mathrm{~min}$ at $30^{\circ} \mathrm{C}$ before analysis by SDS-PAGE and immunoblotting.

\section{$R N A$ interference}

Human haspin validated siRNA (ID \#1093), murine haspin predesigned siRNA (ID \#67120), and negative control 1 or 2 siRNAs (\#4611, \#4613) were from Ambion, and human haspin and negative control SMARTpool siRNAs were from Dharmacon. Haspin SMARTpool siRNA at $50 \mathrm{nM}$ caused a $63 \%$ reduction in haspin mRNA compared with control SMARTpool siRNA in HeLa cells after $30 \mathrm{~h}$ as determined by real-time RT-PCR. Transfection with siRNAs was carried out with siPORT lipid according to the manufacturer's recommendations (Ambion).

\section{Acknowledgments}

We are grateful to Yu Weng and Yuping Sun for technical assistance in preparing recombinant proteins; Hui-Ya Gilbert for her assistance with confocal microscopy; Dr. Mari Porcionatto for help with video microscopy; Stuart Levine, Dr Robert Kingston, and Dr Gavin Schnitzler for gifts of reagents; and Drs Michael Brenner, David Pellman, and Beth Sullivan for useful discussions. This work was funded by grants to J.M.G.H. from the NIH (HD043833) and the William F. Milton Fund of Harvard University.

\section{References}

Adams, R.R., Maiato, H., Earnshaw, W.C., and Carmena, M. 2001. Essential roles of Drosophila inner centromere protein (INCENP) and aurora B in histone H3 phosphorylation, metaphase chromosome alignment, kinetochore disjunction, and chromosome segregation. J. Cell. Biol. 153: 865880.

Aihara, H., Nakagawa, T., Yasui, K., Ohta, T., Hirose, S., Dhomae, N., Takio, K., Kaneko, M., Takeshima, Y., Muramatsu, M., et al. 2004. Nucleosomal histone kinase-1 phosphorylates H2A Thr 119 during mitosis in the early Drosophila embryo. Genes \& Dev. 18: 877-888.

Andrews, P.D., Knatko, E., Moore, W.J., and Swedlow, J.R. 2003. Mitotic mechanics: The auroras come into view. Curr. Opin. Cell. Biol. 15: 672-683.

Barr, F.A., Sillje, H.H., and Nigg, E.A. 2004. Polo-like kinases and the orchestration of cell division. Nat. Rev. Mol. Cell. Biol. 5: 429-440.

Bischoff, J.R., Anderson, L., Zhu, Y., Mossie, K., Ng, L., Souza, B., Schryver, B., Flanagan, P., Clairvoyant, F., Ginther, C., et al. 1998. A homologue of Drosophila aurora kinase is oncogenic and amplified in human colorectal cancers. EMBO J. 17: 3052-3065.

Carmena, M. and Earnshaw, W.C. 2003. The cellular geography of aurora kinases. Nat. Rev. Mol. Cell. Biol. 4: 842-854.

Cho, R.J., Campbell, M.J., Winzeler, E.A., Steinmetz, L., Conway, A., Wodicka, L., Wolfsberg, T.G., Gabrielian, A.E., Landsman, D., Lockhart, D.J., et al. 1998. A genome-wide transcriptional analysis of the mitotic cell cycle. Mol. Cell 2: $65-73$.

Chu, S., DeRisi, J., Eisen, M., Mulholland, J., Botstein, D., Brown, P.O., and Herskowitz, I. 1998. The transcriptional program of sporulation in budding yeast. Science 282: 699705.

Clayton, A.L. and Mahadevan, L.C. 2003. MAP kinase-mediated phosphoacetylation of histone $\mathrm{H} 3$ and inducible gene regulation. FEBS Lett. 546: 51-58.

Coligan, J.E., Kruisbeek, A.M., Margulies, D.H., Shevach, E.M., and Strober, W. 1994. Current protocols in immunology. In Current protocols (ed. R. Coico), Chapter 8. John Wiley \& Sons, Inc., New York.

Crosio, C., Fimia, G.M., Loury, R., Kimura, M., Okano, Y., Zhou, H., Sen, S., Allis, C.D., and Sassone-Corsi, P. 2002. Mitotic phosphorylation of histone H3: Spatio-temporal regulation by mammalian Aurora kinases. Mol. Cell. Biol. 22: $874-885$.

De Souza, C.P., Osmani, A.H., Wu, L.P., Spotts, J.L., and Osmani, S.A. 2000. Mitotic histone H3 phosphorylation by the NIMA kinase in Aspergillus nidulans. Cell 102: 293-302.

Ditchfield, C., Johnson, V.L., Tighe, A., Ellston, R., Haworth, C., Johnson, T., Mortlock, A., Keen, N., and Taylor, S.S. 2003. Aurora B couples chromosome alignment with anaphase by targeting BubR1, Mad2, and Cenp-E to kinetochores. J. Cell. Biol. 161: 267-280.

Fischle, W., Wang, Y., and Allis, C.D. 2003a. Binary switches and modification cassettes in histone biology and beyond. Nature 425: 475-479.

. 2003b. Histone and chromatin cross-talk. Curr. Opin. Cell. Biol. 15: 172-183.

Giet, R. and Glover, D.M. 2001. Drosophila aurora B kinase is required for histone $\mathrm{H} 3$ phosphorylation and condensin recruitment during chromosome condensation and to organize the central spindle during cytokinesis. J. Cell. Biol. 152: 669682.

Goto, H., Tomono, Y., Ajiro, K., Kosako, H., Fujita, M., Sakurai, M., Okawa, K., Iwamatsu, A., Okigaki, T., Takahashi, T., et al. 1999. Identification of a novel phosphorylation site on histone $\mathrm{H} 3$ coupled with mitotic chromosome condensation. J. Biol. Chem. 274: 25543-25549.

Goto, H., Yasui, Y., Nigg, E.A., and Inagaki, M. 2002. Aurora-B 
phosphorylates histone $\mathrm{H} 3$ at serine 28 with regard to the mitotic chromosome condensation. Genes Cells 7: 11-17.

Hauf, S., Cole, R.W., LaTerra, S., Zimmer, C., Schnapp, G., Walter, R., Heckel, A., van Meel, J., Rieder, C.L., and Peters, J.M. 2003. The small molecule Hesperadin reveals a role for Aurora $\mathrm{B}$ in correcting kinetochore-microtubule attachment and in maintaining the spindle assembly checkpoint. J. Cell. Biol. 161: 281-294.

Hendzel, M.J., Wei, Y., Mancini, M.A., Van Hooser, A., Ranalli, T., Brinkley, B.R., Bazett-Jones, D.P., and Allis, C.D. 1997. Mitosis-specific phosphorylation of histone H3 initiates primarily within pericentromeric heterochromatin during G2 and spreads in an ordered fashion coincident with mitotic chromosome condensation. Chromosoma 106: 348-360.

Higgins, J.M.G. 2001a. The Haspin gene: Location in an intron of the Integrin $\alpha \mathrm{E}$ gene, associated transcription of an Integrin $\alpha$ E-derived RNA and expression in diploid as well as haploid cells. Gene 267: 55-69.

- 2001b. Haspin-like proteins: A new family of evolutionarily conserved putative eukaryotic protein kinases. Protein Sci. 10: 1677-1684.

- 2003. Structure, function and evolution of haspin and haspin-related proteins, a distinctive group of eukaryotic protein kinases. Cell. Mol. Life Sci. 60: 446-462.

Hochstenbach, F., David, V., Watkins, S., and Brenner, M.B. 1992. Endoplasmic reticulum resident protein of 90 kilodaltons associates with the $\mathrm{T}$ - and B-cell antigen receptors and major histocompatibility complex antigens during their assembly. Proc. Nat1. Acad. Sci. 89: 4734-4738.

Hsu, J.Y., Sun, Z.W., Li, X., Reuben, M., Tatchell, K., Bishop, D.K., Grushcow, J.M., Brame, C.J., Caldwell, J.A., Hunt, D.F., et al. 2000. Mitotic phosphorylation of histone $\mathrm{H} 3$ is governed by Ipl1/aurora kinase and Glc7/PP1 phosphatase in budding yeast and nematodes. Cell 102: 279-291.

Jenuwein, T. and Allis, C.D. 2001. Translating the histone code. Science 293: 1074-1080.

Johnson, V.L., Scott, M.I., Holt, S.V., Hussein, D., and Taylor, S.S. 2004. Bub1 is required for kinetochore localization of BubR1, Cenp-E, Cenp-F and Mad2, and chromosome congression. J. Cell. Sci. 117: 1577-1589.

Kimura, H. and Cook, P.R. 2001. Kinetics of core histones in living human cells: Little exchange of $\mathrm{H} 3$ and $\mathrm{H} 4$ and some rapid exchange of H2B. J. Cell. Biol. 153: 1341-1353.

Kung, A.L., Sherwood, S.W., and Schimke, R.T. 1990. Cell linespecific differences in the control of cell cycle progression in the absence of mitosis. Proc. Natl. Acad. Sci. 87: 9553-9557.

Lachner, M. and Jenuwein, T. 2002. The many faces of histone lysine methylation. Curr. Opin. Cell. Biol. 14: 286-298.

Luger, K., Rechsteiner, T.J., Flaus, A.J., Waye, M.M., and Richmond, T.J. 1997. Characterization of nucleosome core particles containing histone proteins made in bacteria. J. Mol. Biol. 272: 301-311.

Nigg, E.A. 2001. Mitotic kinases as regulators of cell division and its checkpoints. Nat. Rev. Mol. Cell. Biol. 2: 21-32.

Petersen, J., Paris, J., Willer, M., Philippe, M., and Hagan, I.M. 2001. The S. pombe aurora-related kinase Ark1 associates with mitotic structures in a stage dependent manner and is required for chromosome segregation. J. Cell. Sci. 114: 43714384.

Polioudaki, H., Markaki, Y., Kourmouli, N., Dialynas, G., Theodoropoulos, P.A., Singh, P.B., and Georgatos, S.D. 2004. Mitotic phosphorylation of histone $\mathrm{H} 3$ at threonine 3. FEBS Lett. 560: 39-44.

Preuss, U., Landsberg, G., and Scheidtmann, K.H. 2003. Novel mitosis-specific phosphorylation of histone H3 at Thr11 mediated by Dlk/ZIP kinase. Nucleic Acids Res. 31: 878-885.
Prigent, C. and Dimitrov, S. 2003. Phosphorylation of serine 10 in histone H3, what for? J. Cell. Sci. 116: 3677-3685.

Schaar, B.T., Chan, G.K., Maddox, P., Salmon, E.D., and Yen, T.J. 1997. CENP-E function at kinetochores is essential for chromosome alignment. J. Cell. Biol. 139: 1373-1382.

Schneider, R., Bannister, A.J., Myers, F.A., Thorne, A.W., CraneRobinson, C., and Kouzarides, T. 2004. Histone H3 lysine 4 methylation patterns in higher eukaryotic genes. Nat. Cell. Biol. 6: 73-77.

Schurter, B.T., Koh, S.S., Chen, D., Bunick, G.J., Harp, J.M., Hanson, B.L., Henschen-Edman, A., Mackay, D.R., Stallcup, M.R., and Aswad, D.W. 2001. Methylation of histone H3 by coactivator-associated arginine methyltransferase 1. Biochemistry 40: 5747-5756.

Shannon, K.B. and Salmon, E.D. 2002. Chromosome dynamics: New light on Aurora B kinase function. Curr. Biol. 12: R458R460.

Sharrocks, A.D. 1994. A T7 expression vector for producing Nand C-terminal fusion proteins with glutathione S-transferase. Gene 138: 105-108.

Shoemaker, C.B. and Chalkley, R. 1980. H3-specific nucleohistone kinase of bovine thymus chromatin: Purification, characterization, and specificity for threonine residue 3. J. Biol. Chem. 255: 11048-11055.

Spector, D.L., Goldman, R.D., and Leinward, L.A. 1997. Cells: A laboratory manual. Cold Spring Harbor Laboratory Press, Cold Spring Harbor, NY.

Spellman, P.T., Sherlock, G., Zhang, M.Q., Iyer, V.R., Anders, K., Eisen, M.B., Brown, P.O., Botstein, D., and Futcher, B. 1998. Comprehensive identification of cell cycle-regulated genes of the qeast Saccharomyces cerevisiae by microarray hybridization. Mol. Biol. Cell. 9: 3273-3297.

Sullivan, B.A. and Karpen, G.H. 2004. Centromeric chromatin exhibits a histone modification pattern that is distinct from both euchromatin and heterochromatin. Nat. Struct. Mol. Biol. 11: 1076-1083.

Swedlow, J.R. and Hirano, T. 2003. The making of the mitotic chromosome: Modern insights into classical questions. Mol. Cell 11: 557-569.

Tanaka, T.U. 2002. Bi-orienting chromosomes on the mitotic spindle. Curr. Opin. Cell Biol. 14: 365-371.

Tanaka, H., Yoshimura, Y., Nishina, Y., Nozaki, M., Nojima, H., and Nishimune, Y. 1994. Isolation and characterization of cDNA clones specifically expressed in testicular germ cells. FEBS Lett. 355: 4-10.

Tanaka, H., Yoshimura, Y., Nozaki, M., Yomogida, K., Tsuchida, J., Tosaka, Y., Habu, T., Nakanishi, T., Okada, M., Nojima, H., et al. 1999. Identification and characterization of a haploid germ cell-specific nuclear protein kinase (haspin) in spermatid nuclei and Its effects on somatic cdells. J. Biol. Chem. 274: 17049-17057.

Tanaka, H., Iguchi, N., Nakamura, Y., Kohroki, J., Egydio de Carvalho, C., and Nishimune, Y. 2001. Cloning and characterization of human haspin gene encoding haploid germ cellspecific nuclear protein kinase. Mol. Hum. Reprod. 7: 211218.

Taylor, S.S. and McKeon, F. 1997. Kinetochore localization of murine Bubl is required for normal mitotic timing and checkpoint response to spindle damage. Cell 89: 727-735.

Turner, B.M. 2002. Cellular memory and the histone code. Cell 111: 285-291.

Vandre, D.D. and Borisy, G.G. 1989. Anaphase onset and dephosphorylation of mitotic phosphoproteins occur concomitantly. J. Cell Sci. 94: 245-258.

Van Hooser, A., Goodrich, D.W., Allis, C.D., Brinkley, B.R., and Mancini, M.A. 1998. Histone H3 phosphorylation is re- 
Dai et al.

quired for the initiation, but not maintenance, of mammalian chromosome condensation. J. Cell Sci. 111: 3497-3506.

Wei, Y., Yu, L., Bowen, J., Gorovsky, M.A., and Allis, C.D. 1999. Phosphorylation of histone $\mathrm{H} 3$ is required for proper chromosome condensation and segregation. Cell 97: 99-109.

Yoshimura, Y., Tanaka, H., Nozaki, M., Yomogida, K., Yasunaga, T., and Nishimune, Y. 2001. Nested structure of haploid germ cell specifc haspin gene. Gene 267: 49-54.

Zeitlin, S.G., Shelby, R.D., and Sullivan, K.F. 2001. CENP-A is phosphorylated by Aurora B kinase and plays an unexpected role in completion of cytokinesis. J. Cell Biol. 155: 11471157. 


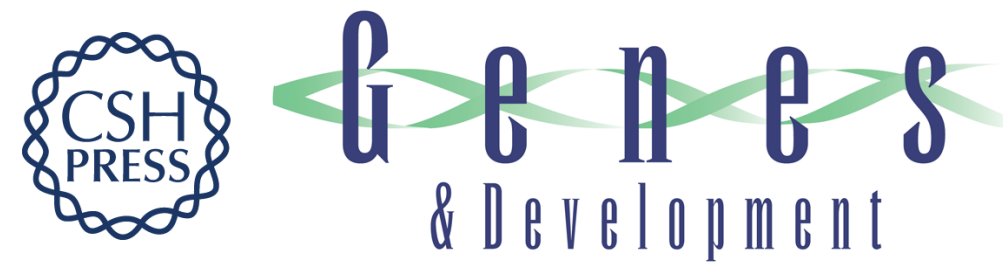

\section{The kinase haspin is required for mitotic histone $\mathrm{H} 3 \mathrm{Thr} 3$ phosphorylation and normal metaphase chromosome alignment}

Jun Dai, Sammy Sultan, Stephen S. Taylor, et al.

Genes Dev. 2005, 19:

Access the most recent version at doi:10.1101/gad.1267105

Supplemental http://genesdev.cshlp.org/content/suppl/2005/01/25/gad.1267105.DC1
Material

References This article cites 54 articles, 22 of which can be accessed free at:

http://genesdev.cshlp.org/content/19/4/472.full.html\#ref-list-1

License

Email Alerting Receive free email alerts when new articles cite this article - sign up in the box at the top

Service right corner of the article or click here.

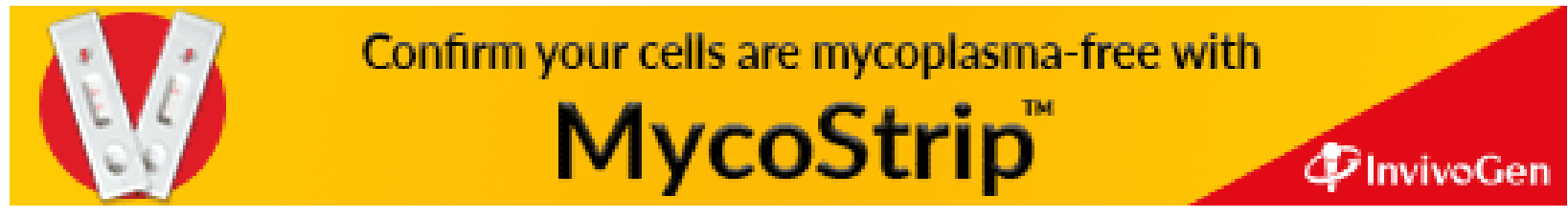

